\title{
Anabases
}

ANABASES Traditions et réceptions de l'Antiquité

16 | 2012

Varia

\section{Henry de Montherlant " entre les deux mondes » : la leçon des manuscrits (I)}

Pierre Duroisin

\section{(2) OpenEdition}

1 Journals

Édition électronique

URL : http://journals.openedition.org/anabases/3909

DOI : 10.4000/anabases.3909

ISSN : 2256-9421

Éditeur

E.R.A.S.M.E.

Édition imprimée

Date de publication : 1 octobre 2012

Pagination : 49-83

ISSN : 1774-4296

\section{Référence électronique}

Pierre Duroisin, « Henry de Montherlant « entre les deux mondes » : la leçon des manuscrits (I) »,

Anabases [En ligne], 16 | 2012, mis en ligne le 01 octobre 2015, consulté le 21 octobre 2019. URL

http://journals.openedition.org/anabases/3909; DOI : 10.4000/anabases.3909

(C) Anabases 
Anabases 16 (2012), p. 49-83.

\section{Henry de Montherlant " entre les deux mondes » : la leçon des manuscrits (I)}

PierRe Duroisin

Je voudrais concilier l'antiquité païenne et le catholicisme, comme la Rome de la Renaissance, une main sur la Louve, une main sur la Croix'1.

Parmi les autographes de Montherlant qui se vendirent le 23 mars 2009 chez Drouot se trouvait un ensemble de " 10 pages in- 4 » daté très précisément du 30 décembre 1922 et intitulé La Garde autour de Pan et Julien l'Apostat ${ }^{2}$. C'est ce dossier qu'on va examiner, à commencer d'ailleurs par son titre, qu'il faut lire en deux temps : Montherlant avait d'abord écrit, à l'encre, La Garde autour de Pan, avant d'ajouter, en

1 Le mot, rapporté par Paul Abraham comme étant de 1924, se trouve dans « Un entretien avec Henry de Montherlant" (Le Mail, $\mathrm{n}^{\circ}$ 1, 1927, p. 8). Remarques pratiques : le lieu d'édition ne sera pas donné s'il s'agit de Paris et pour les œuvres de Montherlant éditées dans la Bibliothèque de la Pléiade, les abréviations E, T, R1 et R2 renverront aux volumes Essais (1963), Théâtre (1972), Romans I (1959, 2008) et Romans II (1982, 2009).

2 Il s'agissait du lot 245 d'une vente organisée par la société Piasa, la date étant celle que Montherlant a notée dans le coin supérieur gauche du premier feuillet : 30-12-1922. La notice du catalogue de vente fait aussi remarquer que la plupart de ces dix pages sont « au dos d'une circulaire de l'EEuvre du souvenir des défenseurs de Verdun - Monument de Douaumont ». Montherlant, comme le rappelle d'ailleurs un post-scriptum de la circulaire, fut le premier secrétaire général de l'Euuvre de l'Ossuaire et le Chant funèbre pour les morts de Verdun qu'il publia en 1925 est l'expression même du soutien qu'il lui apporta entre 1920 et 1924. 
dessous et au crayon, et Julien l'Apostat, comme pour associer l'empereur accusé d'avoir trahi sa foi ${ }^{3}$ au dieu dont la mort avait été annoncée, au i ${ }^{\text {er }}$ siècle de notre ère, à des marins croisant au large de Paxos ${ }^{4}$.

Sur ce diptyque se grefferont, en temps voulu, quelques pages manuscrites vendues de même chez Drouot, le 15 juin 2011, et intitulées, pour la circonstance, «Sur la Religion" $"$.

S’y ajouteront enfin deux inédits, un " conte antique " de 1912 intitulé Le dieu Pan et un petit texte appelé Guerre, qu'on doit à M. Jean-Claude Barat, l'exécuteur testamentaire de Montherlant, de quoi fournir une matière assez riche pour qu'on la répartisse sur deux numéros d'Anabases.

\section{Pan et Julien dans l'œuvre de Montherlant}

La première fois que Montherlant a évoqué La Garde autour de Pan, c'est dans la Nouvelle Revue française du $1^{\mathrm{er}}$ mai 1923, dans des Notes relatives à la religion et aux passions qu'il avait sous-titrées $\grave{A}$ propos $d u$ "Songe ", son roman tout frais paru chez Grasset $^{6}$. Rien d'autre, selon lui, que "des fragments décousus et qui sans mal fussent rentrés au tiroir ${ }^{7}$ ", rien qu' " un tour de valse avec le sacré " où il feint de donner la parole à son héros, un Alban de Bricoule que la "critique catholique " a " déclaré "saugrenu" pour son orgueil, sa "dureté", sa sensualité, son manque de vertus chrétiennes ", mais qui n'en demeure pas moins " un exemplaire du catholique ".

Mis en présence de ses détracteurs, qui lui reprochent de faire "les gestes de la foi " sans avoir la foi, Alban rétorque - ou rétorquerait - qu'il a reçu le Christ dans son héritage et qu'en l'accueillant " avec le reste " (liturgie, sacrements), il se conforme « à

3 Lucien Jerphagnon a remis les choses à leur place quand il a donné pour épigraphe à son Julien dit l'Apostat (Tallandier, 2008) ce mot de Pierre Renucci : " Il nous paraît incongru d'affirmer, d'une façon générale, qu'il y a abandon du christianisme s'il n'y eut au préalable abandon au christianisme. "

4 Grand lecteur des Vies parallèles, Montherlant savait probablement, même s'il ne cite jamais Paxos, que ce soit dans Les Bestiaires en 1925 (R1, p. 578) ou dans Le Solstice de juin en 1940 (E, p. 954), qu'on tient cette légende de Plutarque et de son opuscule sur la disparition des oracles.

5 Il s'agissait du lot 72 d'une vente organisée par Brissonneau, à quoi on associera le texte d'une " Note sur Pour une Vierge noire» qui se vendit chez Piasa le 11 avril 2002.

6 Ces Notes occupent les pages 756 à 769 de la revue. Cela dit, les extraits qu'on en lira ci-après sont repris du placard que Montherlant avait reçu le 13 avril de l'imprimerie Paillart d'Abbeville et qu'il renvoya le 17 avec le bon à tirer, non sans y avoir apporté d'assez nombreuses corrections. C'est de nouveau à M. Barat que je dois d'avoir pu lire ce document qui, comme le texte publié, compte 14 pages.

7 Une variante qui intéressera les historiens de la $N r f$ : « qui sans mal fussent rentrés au tiroir " a, sur le placard même, remplacé " qui fussent rentrés au tiroir sans l'insistance amicale de Jacques Rivière ». 
la recommandation du pontife Aurelius Cotta dans la Nature des dieux, qu' "un bon citoyen accepte la religion des anciens et la pratique parce qu' elle est le fondement de la Cité" ", et quand on le taxe d'hypocrisie, il convoque les "Romains de vieille souche (du type de Celse, de Cœcilius, de Symmaque), qui, devant le christianisme triomphant, refusaient de rompre avec un culte qui avait été mêlé à tout ce qu'il y avait eu de bon et de grand dans leur famille et dans l'Empire et sacrifiaient d'un cœur religieux à une religion à laquelle ils ne croyaient $\operatorname{pas}^{8}$ ".

Et tandis que le héros du Songe se demande si cette «attitude [...] ne fut pas celle de tous les Romains éclairés dès la fin de la République : des pratiquants sans la foi », l'auteur rompt avec la fiction pour feuilleter un album de famille où il se découvre de rudes ancêtres qui tuèrent et pillèrent mais " n'ont pas plus quitté la communauté catholique qu'ils n'ont quitté la communauté nationale ». Rejetant " le vieil esprit de dissociation qui travaille le monde [...], le vieil esprit qui a créé les prétendues antinomies inconciliables entre le corps et l'âme [...], entre le divin et l'humain [...], entre la pensée et l'action [...], entre le christianisme et le paganisme et qui ensuite traite de confusion l'union supérieure qu'il a dans l'abstrait défaite 9 ", il entend rétablir "le mot catholique " dans son statut d'origine, qui est l'universel. Pour lui, pas de doute, c'est le catholicisme qui " a remis debout ce dont le christianisme avait été le principal destructeur $"$ :

" ROMA capta coepit [sic] ferum victorem. Le grand Pan n'est pas mort, et c'est l'Église qui, autour de lui, monte la garde ${ }^{1}$. Un Alban de Bricoule peut être considéré, si l'on veut, comme un de ces produits du monde antique adaptés à la religion nouvelle à laquelle

8 Alban fait allusion au début du chapitre II du livre III, quand Cotta rappelle qu'il s'en tient à la coutume, en tant que pontife aussi bien qu'à titre personnel : " J'ai toujours défendu et défendrai toujours la religion et les cérémonies qui nous sont venues de nos pères ", ajoutant que les auspices, les sacrifices et les prédictions sont pour lui « les fondements de la cité ", fundamenta civitatis. Mais c'est sans doute par La Fin du paganisme de Gaston Boissier que Montherlant découvrit le personnage de Cotta. Boissier, en effet, consacre tout un chapitre de son livre à l'Octavius de Minucius Felix, lequel reprend pour son Caecilius les arguments que Cicéron a mis dans la bouche de Cotta : " La religion nationale est une institution comme les autres, il faut la respecter au même titre. [...] Un bon citoyen l'accepte et la pratique, parce qu'elle est le fondement de la cité. » (G. Boissier, La Fin du paganisme, I, p. 271, Hachette, 1903, 4e éd.). Caecilius rejoint d'ailleurs, dans le discours d'Alban, ces deux défenseurs acharnés du paganisme, l'un du $\mathrm{II}^{\mathrm{e}}$ s., l'autre du IV $\mathrm{e}^{\mathrm{e}}$, que furent Celse et Symmaque, encore que ce rapprochement ne laisse pas de surprendre dans la mesure où, tout à la fin de l'Octavius, le païen Caecilius s'avouera vaincu par son adversaire. Cela dit, le De Natura deorum est un traité sur lequel Montherlant est plusieurs fois revenu : en 1928 dans Jeux olympiques et Antiquité (dans Earinus, Troisième Olympique, p. 137, Hazan, 1929), en 1944 dans La Déesse Cypris (E, p. 1584 dans Textes sous une occupation) et dans les "carnets sans dates et carnets 1972 ", où il le cite d'après d'Yves Battistini (Tous Feux éteints, p. 134, Gallimard, 1975).

On sent poindre le Syncrétisme et alternance de 1925. 
l'Église les incorpora. Je songe à ces divinités champêtres évoquées par Heine, qui, au triomphe du christianisme, se convertirent à la religion nouvelle, parfois même se firent ermites, et mouraient, le chapelet dans les mains, mais le cœur plein de leurs anciennes Arcadies ${ }^{10}$."

C'est ici, dans la note de bas de page correspondant à l'appel inséré par Montherlant après " Le grand Pan n'est pas mort, et c'est l'Église qui, autour de lui, monte la garde ", qu'on aura de quoi faire le lien avec le manuscrit du 30 décembre 1922 :

"Voici l'occasion d'annoncer, à seule fin de prendre date, le livre d'essais qui paraîtra quelque jour sous ce titre : La garde autour de Pan ${ }^{11}$."

Un projet sans lendemain, mais que l'écrivain a pris soin de rappeler à deux reprises au moins et à trente ans d'intervalle : une première fois en 1940, dans Paysage des Olympiques, et une seconde fois en 1972, dans Mais aimons-nous ceux que nous aimons?

1940. L'auteur de Paysage des Olympiques vient de renvoyer le lecteur à Pershing 1920, un essai vieux de vingt ans qui se terminait par une prière à la façon de Socrate : "Ô Dieu des corps et des âmes, donnez-moi de mener une vie juste! Que j’aime toujours davantage les choses que vous avez créées!" doublée d'un mot de MichelAnge : «Car il doit aimer l'œuvre, celui qui en adore l'auteur. "C'est alors qu'il commente pour le lecteur de 1940 :

" Je retrouve dans ce texte cette aspiration vers l'unité qui me hanta jusqu'à ma trentième année environ. Résoudre toutes les antinomies, celles notamment que crée le christianisme, unir par la même piété toutes les croyances et tous les âges, me semblait tâche haute, et d'ailleurs non difficile. [...] Dans un syncrétisme éperdu, je rêvais sur Septime Sévère qui plaça l'image de Jésus au Panthéon, sur cette académie platonicienne de Florence qui s'était proposé formellement pour but de fondre ensemble l'esprit du christianisme et celui du paganisme, sur ce pape Grégoire que Dante fait prier pour l'âme de Trajan. Je méditais de composer un livre, La Garde autour de Pan, où l'on eût soutenu que le christianisme n'est devenu ce qu'il est aujourd'hui que par son alliance avec l'antiquité, que Platon et Aristote restaient incompréhensibles pour les Renaissants, si ceux-ci n'avaient connu Saint Paul et l'Évangile, et qu'enfin c'est dans l'Église seule que l'on peut retrouver vivant quelque chose de l'âme antique ; et déjà je dessinais la couverture du

10 P. 11 sur les épreuves d'imprimerie, p. 766 de la $N r f$. Inutile de préciser que le Roma capta cepit... (car coepit fut corrigé in extremis dans la revue) s'inspire du Graecia capta ferum victorem cepit d'Horace (Ép., II, I, 156).

11 P. 767 de la $N r f$, p. 11 et 12 du placard, où le texte retenu a remplacé «À la seule fin de prendre date, je me permets d'annoncer un livre d'études qui paraîtra quelque jour sous ce titre : La garde autour de Pan ». Pierre Sipriot cite le texte mais sans la note dans Montherlant sans masque, p. 194, Le Livre de Poche, 1990. 
volume : des prêtres en surplis portant sur leurs épaules, avec le plus grand cérémonial, une châsse de verre où repose Pan endormi ${ }^{12}$."

En 1972, quelques semaines avant sa mort volontaire, Montherlant termine Mais aimons-nous ceux que nous aimons?, où il avoue, quand il évoque le temps de ses Olympiques, que s'il n'allait pas à la messe le dimanche tout en disant à sa pieuse et vénérée grand-mère qu'il y était allé, c'était "par indifférence ». La suite nous renverra à Paysage des Olympiques:

"Dans ces années-là, 1920 et 1921, les prêtres cherchaient à annexer le sport parce qu'il était à la mode ; je faisais comme eux non pour les suivre mais parce que mêler christianisme et paganisme était un mouvement inhérent à ma nature, bien que je n'eusse ni foi ni pratique catholique. Je rêvais sur Septime Sévère qui plaça l'image de Jésus au Panthéon ; sur cette académie platonicienne de Florence qui s'était donné formellement pour but de fondre ensemble l'esprit du christianisme et celui du paganisme, sur la phrase de Michel-Ange : "Il doit aimer l'œuvre, celui qui en adore l'auteur. " Je méditais de composer un livre, La Garde autour de Pan - ce qui vit en nous du paganisme nous a été conservé par le catholicisme, - et déjà j'en dessinais la couverture : des prêtres en surplis portant sur leurs épaules, avec le plus grand cérémonial, une châsse de verre dans laquelle repose Pan endormi ${ }^{13}$."

Cela posé, entre la note de 1923 et les textes de 1940 et de 1972, où il est nommément question d'un livre qui devait s'appeler La Garde autour de Pan, s'insèrent deux textes de 1929, Le dernier Retour et Trois Jours au Montserrat, regroupés dès 1930 sous le titre Pour une Vierge noire, puis insérés, en 1945, dans Un Voyageur solitaire est un diable.

Voici d'abord la plainte du Dernier Retour:

"Je suis des trois premiers siècles. Le monde adore le Soleil, et il va se faire chrétien. Je souffre de la souffrance de Pan avant qu'il se fasse chrétien, quand l'Orient lui a tourné la tête.

Le tableau de Signorelli appelé L'École de Pan, et que j'ai toujours appelé La Tristesse de Pan. Si jeune, et quelle mélancolie, sous sa lourde couronne de joie!

Ferrero a un bel essai sur la tristesse des Romains du temps d'Auguste. Flaubert écrit qu'à aucun moment du monde l'homme ne fut aussi seul entre les dieux auxquels il ne

12 Paysage des Olympiques, p. 43-44, Grasset, 1940. Le texte de 1920 auquel renvoie Montherlant avait paru dans Le Monde nouveau de septembre 1920 sous le titre Quant aux Jeux Olympiques... avant d'être inclus en 1929 dans Earinus, sous le titre Pershing 1920. La légende du pape Grégoire priant pour que Trajan ressuscite afin de mourir en chrétien est reprise par Dante au chant XX de son Paradis.

13 Mais aimons-nous ceux que nous aimons?, p. 39-40, Gallimard, 1973. Pour ce qui est de Septime Sévère accueillant Jésus au Panthéon, on verra dans la note 69 ce qu'il y a lieu d'en penser. 
croyait plus, et le dieu auquel il ne croyait pas encore. Pater dit qu'il n'est aucun accent de mélancolie que la fin du paganisme ait ignoré ${ }^{14}$. "

Trois Jours au Montserrat, quant à lui, résulte d'une courte retraite que fit Montherlant à l'abbaye de Montserrat alors qu'il venait de découvrir le jansénisme dans le Port-Royal de Sainte-Beuve ${ }^{15}$.

Notre diable de voyageur a commencé par rappeler que le Montserrat, dénoncé par les chrétiens comme le Mons Luxuriae parce qu'on y avait bâti un éphémère temple à Vénus, fut ainsi "perdu et repris, tour à tour, par Pan et par Jésus-Christ ". Il a ensuite raconté, à sa manière, la légende de Juan Guarin, le jouisseur qui se fait ermite, puis retombe dans le péché (avant de retourner pour de bon à son ermitage) quand "l'esprit de Pan a repris possession du libertin de jadis ». Il a démasqué le Tentateur dans " le petit chat " où Saint-Cyran reconnaissait une créature de Dieu : "Inquiétant petit chat! Je le vois cousin du barbet de Faust. Il est éternel, il est Pan. Il est le Diable, en parler chrétien. " Il tire enfin la leçon du baptême qui, même s'il n'a pas la foi, le " maintient catholique ", estimant qu'il a désormais du catholicisme " une vue plus saine et plus digne que celle qu'[il] en prenai[t], ou plutôt qu'[il] voulai[t] [s]'en faire, autrefois " :

"Chercher à concilier Pan et Jésus-Christ sera toujours un exercice souverain pour vous faire jouir l'imagination, si vous n'êtes pas croyant : cela mène à s'exciter l'esprit, et

14 E, p. 427. D’abord publié dans Les Nouvelles littéraires du 29 mars 1930, Le dernier Retour fut joint à Pour une vierge noire pour l'édition en volume qui parut peu après aux Éditions du Cadran. Le mot de Flaubert (qu'on trouve dans une lettre de 1861 à $\mathrm{M}^{\text {me }}$ Roger des Genettes : "Les dieux n'étant plus et le Christ n'étant pas encore, il y a eu, de Cicéron à Marc-Aurèle, un moment unique où l'homme seul a été "), n'était pas dans la version des Nouvelles littéraires, cependant que le mot de Pater se trouvait sous une forme plus explicite dans Pour l'anniversaire de Paul Adam, un essai que Montherlant publia dans Les Écrits nouveaux de janvier 1921 avant de le reprendre près de dix ans plus tard sous le titre Pour Reims dévastée : "Il n'y a presque pas un accent mélancolique dans l'Église du Moyen Âge que le Polythéisme n'ait connu avant elle. " (Au petit Mutilé, p. 80, Les Éditions du Portique, 1930). Et ce n'est sans doute pas une coöncidence si, dans le même recueil mais dans l'essai intitulé Sur le Malheur des temps, on lit : "Ferrero consacre toute une étude à montrer la tristesse et l'inquiétude des Romains du temps d'Auguste" (ibid., p. 95).

15 Voir à ce sujet la "Note sur "Port-Royal" " jointe au Maître de Santiago (T, p. 526) et aussi Le Treizième César, p. 155, Gallimard, 1970. Le texte qu'on lit sous le titre Trois Jours au Montserrat est en fait composé de deux éléments bien distincts : une brève évocation qui parut d'abord dans L'Intransigeant du 9 mars 1926, puis dans le recueil Trois Images de l'Espagne en 1928, puis dans le recueil Le Génie et les fumisteries du Divin en 1929, sous le titre Remparts flambants du monde (les pages 373 à 375 partim de l'édition de la Pléiade), et l'essai qui fut publié dans Les Nouvelles littéraires des 26 avril et 3 mai 1930 sous le titre Montserrat avant de paraitre sous le titre Pour une vierge noire dans le recueil du même nom publié peu après par le Cadran (l'équivalent, même s'il y aura d'importants ajouts et variantes, des pages 375 à 401 de l'édition de la Pléiade). 
se fouetter le sang [...]. Mais si l'on croit ! Si l'on croit, même en faisant le départ entre ce qu'il y a de vivant et ce qu'il y a de mort dans l'Évangile ! L'Église catholique mêlant Jésus-Christ aux patries, Jésus-Christ à l'argent, Jésus-Christ au sport, que sais-je, donnant pour dames d'honneur à Jésus-Christ les trois Concupiscences en habits de fête, c'est un spectacle qui vous remplit d'une poésie trouble et âcre, si vous êtes au dehors, mais qui vous fige si vous vous mettez seulement un instant dans la peau d'un homme qui aime le Crucifix ${ }^{16}$."

Après 1929, et mis à part un mot des carnets de 1970 sur lequel on reviendra, Pan se fit plus rare dans l'œuvre de Montherlant. Les textes de 1940 et de 1972 ne sont, à tout prendre, que des retours sur le passé, et l'auteur de Paysage des Olympiques a bien dit que "cette aspiration vers l'unité " qui le poussait à " résoudre toutes les antinomies ", ce «syncrétisme éperdu " qui devait déboucher sur La Garde autour de Pan, ne s'étaient guère étendus au-delà de sa trentième année. Le dossier du 30 décembre 1922 se situe donc au nœud de la " crise ", et ce n'est pas un hasard si vers 1925 le héros des Bestiaires, le même que celui du Songe, évoque lui aussi " le syncrétisme éperdu qui bouillonne en lui ${ }^{17}$ ", tout en se réclamant de ce Julien que ledit dossier associe à $L a$ Garde autour de Pan.

Mais avant d'en venir à Julien, il faut parler d'un dieu Pan qui est lié à la jeunesse de l'écrivain et qu'on va découvrir, comme on l'a dit plus haut, grâce à $\mathrm{M}$. Jean-Claude Barat.

L'œuvre, intitulée Le dieu Pan et datée du 7 décembre 1912, devait s’inscrire dans un recueil de Contes antiques. Le Christ est seul et songeur dans la nuit, "parmi les oliviers bleuissants de Gethsémani », quand il voit surgir « une forme étrange » dont les jambes et le front sont ceux d'un bouc ; c'est le grand Pan, qui d'emblée lui reproche d'avoir détruit la beauté :

«Tu as dit : l'âme seule compte, le corps est méprisable. À l'époque du grand Pan, les hommes étaient beaux, robustes et sains. On ne se rassasiait pas de les contempler. Maintenant, absorbés par l'extase spirituelle, ils laissent leur corps s'étioler, et ils le flagellent ; leur visage sera creusé par la pensée, leur dos voûté par l'étude, leur poitrine rentrée, leur peau molle et blanche, car ils savent qu'il n'y a que l'âme qui soit digne d'être cultivée...»

Autre reproche, celui de s'acharner " à perpétuer une espèce dégradée et impropre à la vie, à faire demeurer tout ce qui est médiocre et malingre ", et quand Jésus répond : "La beauté m'est indifférente », Pan rétorque :

" Je te l'avoue, Jésus, aimer mon prochain quand il est bien proportionné, cela m'est facile, et le difficile serait de ne pas l'aimer ; mais aimer les jambes cagneuses, la peau flas-

16 E, p. 377- 378, 396-397 et 399 successivement.

17 E, p. 516. 
que, les ventres proéminents et les mollets grêles, sans compter les trognes que tu devines, je t'assure, Jésus, tu n'aurais pas dû demander cela. [...] Tu as faussé l'esprit des hommes ; tu as introduit un amour maladif pour ce qui est humble, pour ce qui est pauvre, pour ce qui souffre, et c'est contre la nature. Au siècle du grand Pan, l'homme sympathisait avec ce qui est sain, ce qui est beau, ce qui est la vie ; et c'était naturel. Aujourd'hui, il n'aime plus ce qui est parfait, mais ce qui est imparfait. "

Autre reproche encore, celui d'avoir " créé le péché » en même temps qu’une " vertu impraticable " et sans grandeur :

"La vertu n'est vertu que désintéressée. Tout acte de vertu qu’on fera, on le fera par peur de ton enfer, et dans ton ciel immoral, il n’y aura que les égoïstes et les lâches!»

Tant et si bien que le Christ perd contenance. Quand les hommes d'armes viennent l'arrêter, il s'étonne que Pan ne l'ait pas plus tôt tué, qu'il ne le tue pas en cet instant même, mais le faune lui répond en baissant la tête : "C'est que, moi aussi, je me suis fait chrétien. »

L'attrait qu'exerce la beauté, la répulsion que provoque la laideur seront parmi les thèmes cardinaux, d'ailleurs hérités de Platon, de Thrasylle, un " conte antique " lui aussi, que Montherlant commence de rédiger en $1913^{18}$. Le jeune Thrasylle le dira en des termes qui rappellent ceux de Pan : «N'est-il pas plus logique d'aimer et de choyer la perfection plutôt que l'imperfection quelle qu'elle soit : misère, maladie, bêtise, laideur, insignifiance ${ }^{19}$ ?"

L'exaltation du corps, avant d'être au cour des Olympiques, sera dans Pershing 1920, où l'écrivain vitupère les « misérables intellectuels " qui « du fond de leurs tristes tanières, laids, exsangues et pas soignés [...] ont décrété le divorce entre christianisme et paganisme ", semant " la tristesse sur la terre avec leurs interdictions et leurs exclusions $^{20}$ ".

Le refus de l'" amour maladif pour ce qui est humble, pour ce qui est pauvre, pour ce qui souffre ", avant d'être martelé dans l'Appendice nietzschéen des Lépreuses ${ }^{21}$, sera dénoncé en 1926 dans La Mort de Peregrinos, qu'on retrouvera d'ailleurs dans le manuscrit de $1922^{22}$.

18 Voir P. Duroisin, "Henry de Montherlant et L'Amitié antique de Ludovic Dugas : les dessous et les à-côtés d'un manuscrit ", Bulletin de l'Association Guillaume Budé, 20102012, p. 173-184.

19 Ibid., p. 165-169 et Thrasylle, p. 52, Laffont, 1984.

20 Earinus, p. 68-69, Hazan 1929 (repris dans Paysage des Olympiques, p. 36-37).

21 R1, p. 1537 notamment. À noter que Montherlant ne découvrit Nietzsche qu'en 1916 (voir J.-N. Faure-Biguet, Les Enfances de Montherlant, Paris, Plon, 1941, p. 170 et p. 171).

22 Quand Peregrinos est emprisonné pour s'être converti au christianisme, autour de lui s'empresse une "multitude de pauvres types, esclaves, vieillards, femmes, orphelins, et 
Le ciel " immoral » où le faune de 1912 ne trouve "que les égoïstes et les lâches » annonce la conclusion de Trois Jours au Montserrat, où l'écrivain ne voit dans l'espérance qu'un "daemon funeste aux hommes ", estimant qu' " une grande âme, et qui douterait de son immortalité, devrait vivre et mourir comme si elle la niait ", et que " c'est bien désespérer de l'humanité, que penser qu'il lui faut une religion pour être haute et pour être honnête ${ }^{23}$ ".

Comment, enfin, ne pas penser, devant ce Pan de 1912 qui confesse : "Moi aussi, je me suis fait chrétien ", à celui auquel s'assimilera, en 1929, l'auteur du Dernier Retour : "Je souffre de la souffrance de Pan avant qu'il se fasse chrétien, quand l'Orient lui a tourné la tête" ? Déchirements d'un jeune adulte, puis d'un homme fait qui jusqu'en 1925 (il l'a dit en termes exprès dans l'avant-propos de Service inutile) était " imbu des sine caritate Romani » tout en "faisant joujou " avec le christianisme ${ }^{24}$.

Pour le Grand Pan, on est parti des Notes relatives à la religion et aux passions de 1923 ; pour Julien, il faut commencer par deux témoignages : celui de JacquesNapoléon Faure-Biguet, ami d'enfance de Montherlant, qui rapporte qu' « en 1922, tandis que les catholiques célébraient la Relève du Matin, il méditait déjà d'écrire une vie de Julien l'Apostat, et, enflammé par son modèle, louait un petit logement rue de la Harpe, afin d'être tout proche des thermes de Julien ${ }^{25}$ ", et celui de l'écrivain lui-même, qu'on lira dans Moustique, un récit des années vingt mais publié après sa mort :

" J'ai loué à Paris un petit appartement meublé. Malgré le quartier que j’ai en horreur, je me suis décidé pour lui parce que, de mes fenêtres, je vois les thermes de Julien, que les chrétiens appellent l'Apostat ${ }^{26}$."

Cette dévotion pour Julien, comme on l'a dit plus haut, Montherlant la prêtera bientôt au Bricoule des Bestiaires, roman qui paraît en 1926. Fort travaillé par « la religion du Taureau " et les légendes entourant Mithra, Bricoule est aussi un admirateur de Julien :

"Son esprit voletait avec insistance autour de l'empereur Julien, - et Julien était un fervent de Mithra, dont il célébrait les mystères dans son palais de Constantinople ${ }^{27}$. "

De là vient sans doute qu'en 1925 l'auteur d'Aux Fontaines du désir, devant une mosquée de Tolède convertie en église, imaginait que "quelque Julien, restaurant

de ratés de toutes sortes ", en bref "les adeptes habituels du "sophiste crucifié" " (E, p. 250).

23 R1, p. 400-401.

24 E, p. 577-578. L'avant-propos de Service inutile est de 1935.

25 Les Enfances de Montherlant, p. 176.

26 Moustique, p. 113, La Table Ronde, 1986.

27 R1, p. 513. Pour l'origine de la relative " dont il célébrait... », voir P. Duroisin, Montherlant et l'Antiquité, Bibl. de la Faculté de Philosophie et Lettres de l'Ulg, CCL, Paris, Les Belles Lettres, 1987, p. 230. 
Pallas Athéné, l'installerait dans Notre-Dame de Paris ${ }^{28}$ ", et qu'en 1929 l'auteur de Trois Jours au Montserrat, rappelant que "c'est toujours dans les grottes que devait être célébré le culte de Mithra ", évoque à nouveau Julien, même si l'image qu'il s'en fait alors est un peu écornée :

"Souvent, sur ces hauteurs aimées des aigles [...], m’est apparu le Génie de l'Empire, tenant une proie dans sa bouche pleine de sang. Julien, auquel il se montra deux fois, le vit plus aimable. Mais Julien n'était pas tout à fait celui dont ont soif nos imaginations romantiques, le jeune homme brûlant et dur, voué par son double baptême d'eau chrétienne et de sang de taureau à un grand destin ambigu ; c'était un foutriquet hirsute, au nez en l'air, "à peine un homme”, dit Ammien Marcellin, et l'on comprend que ses visitations aient été d'une nature un peu éthérée ${ }^{29}$."

Aigreur toute passagère si l'on en juge par la Lettre à $M$. Pioch, maire des SaintesMaries, sur le sacrifice du Taureau et la sauvegarde du Vaccarès qui parut dans Comoedia le 13 juin 1930.

Sollicité pour faire partie du Comité des Fêtes du Centenaire de Mistral pour la Camargue, Montherlant commence par renvoyer le lecteur au "paganisme toujours respirant sur la montagne catalane du Montserrat " qu'il vient de célébrer dans Pour une Vierge noire (le futur Trois Jours au Montserrat), avant de se réjouir de ce que «la même voix " lui arrive "d'un autre sanctuaire méditerranéen " : "C'est la voix de la Bonne Nouvelle, qui dément celle que Tibère entendit sur les eaux : "Le Grand Pan n'est pas mort !" "Suit la lettre au maire, où il dit son émotion à l'idée du " peuple méridional rallumant le feu générateur et pacificateur allumé par Aurélien et Julien contre la menace chrétienne, comme ces feux qu'on allume, en Afrique, autour des campements, contre les bêtes sinistres de la nuit ». Un bel élan de lyrisme, mais qui débouche sur un refus : "Il n'eût manqué à ma joie que celle d'être moi-même le sacrificateur. J'aurais pu l'être il y a quelques années encore. Je ne le peux plus ${ }^{30}$. "

Pourquoi "Je ne le peux plus »? Jean Datain eut raison de suggérer qu'après Montserrat, où s'exprimait encore "le regret de ne pouvoir concilier Pan et JésusChrist ", Montherlant s'en tint à l'alternance parce qu'il avait admis que "les syncrétismes ne pouvaient demeurer qu'à l'état de vœu ${ }^{31}$ ", mais enfin ce refus n'était pas

28 E, p. 274.

29 E, p. 380. Pour la lecture quelque peu maligne du texte d'Ammien (Mediocris erat staturae...), voir P. Duroisin, Montherlant et l'Antiquité, p. 21.

30 Jean José Marchand, Montherlant, Paris, Éd. Jean-Michel Place, Archives du xx siècle, 1980, p. 89-90, où l'article de Comoedia, dont le brouillon fut vendu chez Drouot le 23 mars 2009, est repris sous le titre Le Grand Pan n'est pas mort. Pour le fond, on a noté le raccourci à propos de Tibère, à qui le cri fatidique fut seulement rapporté, et le rapprochement entre Julien et cet Aurélien qui mérita le surnom de " restaurateur du monde romain " pour avoir réintroduit à Rome le culte du Soleil invincible.

31 Montherlant et l'héritage de la Renaissance, Amiot-Dumont, 1956, p. 68-69. 
un reniement. Julien reviendra dans les carnets de 1931, dans ceux de $1937^{32}$ et dans L'Assomption du Roi des Rois en 1942, et ce n'est pas un hasard si Montherlant à deux reprises, en 1942 comme en 1931, cite les mots de Vigny pour qui l'empereur "prend la résolution de se faire tuer quand il est sûr qu'il a été plus avant que les masses stupides et grossières ne peuvent aller ", avant de les commenter, dans une parenthèse peu amène pour les tenants de la religion nouvelle : " (les masses qui veulent être chrétiennes) ${ }^{33}$."

Parenthèse qui va nous ramener à 1940 pour l'essai qui donna son titre au Solstice de juin. On y retrouvera ensemble, comme dans le manuscrit de 1922, le dieu déchu et l'empereur traité d'apostat, Pan à cause de l'annonce de sa mort, Julien pour le mot qu'il aurait prononcé avant de rendre l'âme : "Tu as vaincu, Galiléen. "

L'écrivain est à Marseille, l'armistice a été signé une semaine auparavant, au solstice d'été, et « la croix gammée, qui est la Roue solaire, triomphe en une des fêtes du Soleil » :

"Le soir, j'ai été marcher le long de cette côte livide : quand on arrive du large, comme on voit tout de suite que mon pays a toujours été saigné. Rien n’a lieu sur la grande eau, plus douce que la terre. Elle vague vaguement, jouant un peu sur son bord. Saute parfois une petite vague, comme un chien qui bondit pour avaler une mouche. C'est la mer où une voix passa qui disait : "Le grand Pan est mort", traduisez : "Tu as vaincu, Galiléen." Et où j'entends ce soir une autre voix qui passe : "Tu es vaincu, Galiléen ${ }^{34 ” . ~ " ~}$

Montherlant évoque ensuite le mois qu'il a passé dans la zone des armées, entre le 20 mai et le 20 juin, comme correspondant de guerre de Marianne. Il y eut d'abord l'attente :

"J'étais parmi les troupes chrétiennes et numides, et les nègres portant au poignet des "Immaculée Conception" pour grigris. Longtemps j’avais eu faim de voir cette armée en face, et de savoir quelle était sa contenance, quels étaient ces hommes "qui nomment dieu le secret des bois" [en note : Tacite, La Germanie] ; dont c'était la gloire ancienne d'avoir haï le christianisme [en note : Goethe, Xénies], et dont maintenant c'était la mission de ruiner la morale bourgeoise et la morale ecclésiastique, depuis les rives de l'Atlantique jusqu'aux marches de Russie ${ }^{35}$."

32 E, p. 989 et 1217 respectivement. Le lecteur pouvait s'attendre à ce qu'on mentionne ici les carnets de 1930, où l'écrivain se réfere à la Nouvelle Histoire romaine de Léon Homo pour évoquer les empereurs qui, avant de mourir, demandent à boire : Néron, Othon et Julien (E, p. 987). Les références que donne Montherlant (p. 340, 341 et 501) sont bien exactes, mais l'ouvrage de Homo n'ayant paru qu'en 1941 chez Arthème Fayard, puis, en 1943, chez Firmin Didot, c'est évidemment par erreur que cette note fut insérée dans des carnets de 1930.

33 E, p. 1445 dans Textes sous une occupation.

34 E, p. 954.

35 Ibid., p. 955. 
Puis vint la débâcle, qui de nouveau appelle le mot de Tacite, associé au retour de Julien :

"À nos trousses, la païennie déferlait, ses casques ceints de couronnes de branchages : "Ils nomment dieu le secret des bois" [...]. Et je pensais que la terre qu'elle gagnait maintenant lui était acquise [...], et qu'un jour viendrait où je verrais flotter l'étendard de la Roue solaire sur les tours de Notre-Dame de Paris. La cité n'était plus la cité de Geneviève, mais la cité de Julien. Le pays n'était plus le pays des Saintes, mais le pays de l'Empereur. »

Des lignes assez dures pour que l'auteur (Christopher Gérard l'a noté dans son essai sur Julien) décide de les éliminer de la version revue du Solstice ${ }^{36}$, des lignes qui lui furent vivement reprochées en 1945 et lui sont encore reprochées aujourd'hui, bien qu'elles soient dans le droit fil de ce qu'il disait en 1925 devant la mosquée de Tolède transformée en église, dans le droit fil aussi des Notes relatives à la religion et aux passions de mai 1923, parentes enfin, ne serait-ce que par l'allusion à Tacite, de cette page du Songe où Bricoule considère, sur sa table de travail, le christ d'ivoire qu'il " avait nommé Génie de son travail »:

"Il lui avait demandé davantage de valeur, demandé le pouvoir de créer la phrase secrète qui rapprocherait de son autel "ceux qui nomment Dieu le secret des bois". Et telle était la disposition du lieu, que, lorsqu'il était à sa table, le jeune homme s'apercevait, sous le geste de ce christ, réfléchi dans la vitre de sa bibliothèque [...]. Et à côté d'eux, suspendu dans l'air, vrai spectre d'un monde refroidi, un diaphane visage féminin [...] : le marbre rapporté d'Achaïe [...], qui du fond de la pièce venait mettre son image [...] auprès des images d'Alban et de la Croix ${ }^{37}$."

Le voilà bien le héros "saugrenu " qui déplut aux lecteurs catholiques du Songe, celui qui attend d'un crucifix qu'il lui souffle les mots capables de réaliser l'utopie que son créateur entretint "jusqu'à sa trentième année environ » (on en revient une fois de plus à Paysage des Olympiques) et qui était d'" unir par la même piété toutes les croyances et tous les âges ". Ce n'était pourtant, ici encore, que l'amorce de ce que dira en 1925 l'auteur de Syncrétisme et alternance quand à l'élan syncrétiste il associera la nécessité "d'alterner les idéals ${ }^{38}$ ", l'amorce aussi de ce que le Montherlant du Solstice jugera bon de rappeler à ses lecteurs de 1941 lorsque, dans une note fort explicite et

36 Voir Julianus Redivivus, Bruxelles, Antaios, 2002, p. 16 (repris dans La Source pérenne, Lausanne, L'Âge d'Homme, 2007). Pour ce passage du Solstice, voir la p. 303 de l'édition originale publiée par Grasset en 1941.

37 R1, p. 12-13. Entre Le Songe et Le Solstice de juin, on aura cette application très particulière de la formule de Tacite dans les carnets de 1934 : «Arrivé au nid de toutes les délices, qui était un beau bosquet, je me redisais le mot de Tacite sur les Germains : "Ils nomment dieu le secret des bois" " (E, p. 1114).

38 E, p. 244. 
dont nul ne fit grand cas, il les renverra à ses écrits des années vingt et trente, dont le fameux essai, précisément, de $1925^{39}$.

On s'étonne moins, après cela, de retrouver dans Le Solstice le mot de Tacite qu'on a lu dans Le Songe, à vrai dire sorti des Mémoires d'outre-tombe que le soldat Montherlant s'était fait envoyer par sa grand-mère fin 1917, quand il était à Mirecourt dans les Vosges ${ }^{40}$.

Chateaubriand vient d'exalter "la jeune Allemagne » de 1813 qui s'est rebellée contre Napoléon ; il commente : «Les Allemands adorent aujourd'hui la liberté dans un vague indéfinissable, de même qu'autrefois ils appelaient Dieu le secret des bois : Deorumque nominibus appellant secretum illud ${ }^{41}$..." On ne conçoit pas traduction plus libre, ni plus originale, ni qui fasse davantage rêver, pour ces quelques mots de $L a$ Germanie. Montherlant eut la bonne idée de la retenir, mais derrière Chateaubriand, c'est aussi l'étroite parenté du Songe et du Solstice qui s'impose au lecteur, pour lui rappeler qu'il s'agit toujours de la guerre opposant la France à l'Allemagne, autant dire la chrétienté au paganisme.

Pour annoncer La Garde autour de Pan, on avait Le dieu Pan de décembre 1912. On n'aura pas de Julien l'Apostat avant l'heure pour annoncer celui de décembre 1922, mais on tient quand même une piste avec le manuel d'histoire que Montherlant avait utilisé en sixième à Janson de Sailly. Il s'agit en l'occurrence de L'Histoire de l'Antiquité d'Albert Malet, où il a volontiers picoré pour ses écrits de jeunesse et qu'il a consulté sa vie durant ${ }^{42}$. Or on trouve à la page 401 de Malet une illustration qui s'intitule "Restauration d'une partie des thermes de Julien à Paris - Le Frigidarium ", et aux pages 428-429 tout un paragraphe consacré à Julien lui-même :

"La tentative de restauration du paganisme fut l'œuvre de l'empereur Julien, neveu de Constantin, qui était né chrétien. Il avait longtemps vécu à Athènes dans l'étude des belles-lettres et de la philosophie grecque. Quand les guerres civiles l'eurent porté à l'empire, il s'empressa d'abjurer le Christianisme, adopta le culte de Mithra, rouvrit les temples abandonnés et restaura toutes les cérémonies de l'ancien culte. Les Chrétiens le

39 Cette note qui figure aux pages 312 et 313 de l'édition de 1941 du Solstice sera reprise dans l'édition de la Pléiade (E, p. 961), mais elle est nettement plus explicite dans l'édition originale.

40 Voir Album Montherlant de la Bibl. de la Pléiade, p. 78.

41 Mémoires d'outre-tombe, XXII, 5. Pour le De Germania, voir IX, 2 : Lucos ac nemora consecrant deorumque nominibus appellant secretum illud quod sola reverentia vident. " Ils sanctifient les bois et les bosquets et donnent les noms des divinités à ce mystère qu'ils ne voient que par les yeux de la vénération. »)

42 Pour les emprunts des jeunes années, voir P. Duroisin, « Le De Augusto du jeune Henry de Montherlant (suite et fin) ", dans Les Lettres romanes 63/3-4 (2009), p. 242-243, et plus encore des textes inédits des années 1906-1907 comme Suprême défi et Nadia. Pour les témoignages de l'âge mûr, voir Port-Royal et le puritanisme romain (T, p. 921) ou le texte intitulé Poissons (Coups de soleil, Paris, Gallimard, 1972, p. 186). 
surnommèrent l'Apostat. Cependant il ne procéda pas à des persécutions sanglantes. Il disait lui-même : "J'ai résolu d'user de douceur et d'humanité envers tous les Galiléens." Mais il s'efforça de ruiner leur influence ; il les exclut des fonctions publiques et leur interdit d'enseigner les lettres profanes en leur disant : "Contentez-vous de croire et cessez de vouloir connaître." Sa tentative n'aboutit pas ; car il mourut bientôt dans une expédition contre les Perses (360-363). - Il avait, au début de son règne, résidé à Lutèce-Paris, et il avait embelli ce séjour qu'il affectionnait. Il reste de lui des Thermes, qui sont aujourd'hui compris dans le Musée de Cluny. »

Pour un jeune lecteur qui avait "sauté dans Quo vadis les pages consacrées à l'apôtre Pierre ${ }^{43}$ ", il y avait là matière à réflexion et à rêveries.

\section{Le manuscrit du 30 décembre 1922}

Quand on a devant soi un ensemble de pages qui ne sont pas numérotées ou ne le sont que partiellement, on commence par les lire dans l'ordre où elles se présentent, quitte à le modifier ensuite, s'il apparaît qu'il n'était pas le plus approprié. Qu'en est-il dans le cas présent?

Pour la première et la dernière page, c'est assez simple. D’abord maintenue par une épingle qui laissa une marque dans le coin supérieur gauche de chaque page ${ }^{44}$, la liasse le fut ensuite par deux trombones juxtaposés qui laissèrent eux aussi leur empreinte sur les dix pages. L'un des trombones a de surcroît déposé de sa rouille au recto d'une page qui est tout justement celle portant la date et le double titre, ainsi qu'au verso d'une autre page qu'on tiendra, en principe, pour la dernière ${ }^{45}$. Suivront six pages, dont cinq numérotées par Montherlant, qui développent le canevas figurant sur la première. Pour les trois dernières pages, essentiellement consacrées à Julien, on renvoie le lecteur au n ${ }^{\circ} 17$ d'Anabases.

Une autre difficulté surgit quand on entreprend de transcrire le manuscrit, Montherlant ayant semé des notes et des références un peu partout : dans la marge de gauche le plus souvent (si on peut parler de marge), mais aussi, parfois, en bas de page, voire au verso. Une note en italique et entre crochets droits précisera leur place sur la page.

43 C'est ce qu'affirme Montherlant de l'Alban des Bestiaires (R1, p. 385), mais qui va dans le sens de ce qu'il dira pour lui-même dans Le Treizième César, p. 151 à 155.

44 En l'espèce, deux petits trous distants d'un peu moins de $2 \mathrm{~cm}$.

45 Pour les plus minutieux, on dira pourquoi l'épingle, dont la tête et l'extrémité laissèrent elles aussi un point de rouille sur le premier et le dernier feuillet, précéda les trombones. Dans l'angle supérieur gauche de l'une des pages numérotées par ses soins, Montherlant a collé un bout de papier destiné à corriger la numérotation ; or ce bout de papier a masqué les trous de l'épingle, mais il porte les empreintes des trombones. 
Les remords de l'écrivain seront soigneusement notés : les mots barrés seront repris comme tels, et les corrections signalées par un espacement étendu.

La lecture et le commentaire se feront par tranches, en fonction de la teneur même du document. On lira d'abord la première page, où figure, en cinq points, le plan de $L a$ Garde autour de Pan, puis les six pages où ces cinq points sont inégalement développés, les trois dernières pages étant, comme on vient de le dire, renvoyées à plus tard.

Dernière remarque : pour éviter toute confusion entre les pages numérotées par Montherlant et les pages du manuscrit en tant que tel, on parlera désormais de pages et de feuillets.

FEUILLET 1

30-12-1922 [coin supérieur gauche]

La Garde autour de Pan. et Julien l'Apostat [ajouté au crayon]

1. comment ils deviennent amis ds le Nord

2. leur dignité

lui se sent romain et antique, uniquement

l'autre est devant lui un nazaréen

(de ma part aucune idée de conciliation : tout d'une pièce, antique)

3. aux thermes de Julien

il est le symbole de l'envie de retour au paganisme

le grand Pan est mort

la tristesse de Pan

les dieux en exil

tjrs antique tout d'une pièce [dans la marge en regard des quatre lignes précédentes]

4. Dans les Vosges

Kyriolés - Pagani

Il voit que toutes choses sont l'une et l'autre

Symphonie : vœu de conciliation.

\section{Office}

Se rend compte que le catholicisme a tué le christianisme et est en réalité le paganisme continué, tout ce qui nous reste de vivant de la res romana. Certitude joyeuse

Que voilà un plan des plus précis pour... mais pour quoi au fait ? Un « livre d'essais " comme annoncé dans la $N r f$ du $1^{\text {er }}$ mai 1923 ? Les cinq temps que définit ce 
plan donnent plutôt l'idée d'un récit unique avec une structure bien charpentée et des péripéties qui se déroulent dans le Nord, puis à Paris-Lutèce, puis dans les Vosges.

Acte I. C'est dans le Nord que les protagonistes se rencontrent et se lient d'amitié. Quel Nord ? L'auteur lui-même n'y a, semble-t-il, pensé qu'après coup, un blanc séparant très nettement les groupes de mots " comment ils deviennent amis " et " dans le Nord".

Acte II. Cette amitié n'entame nullement les convictions des deux hommes, du Romain comme du pseudo-Nazaréen. Mais s'ils ont l'un et l'autre "leur dignité » (un mot qui s'éclairera plus loin), l'auteur insiste sur le caractère entier du païen : "Lui se sent romain et antique, uniquement ", " de ma part aucune idée de conciliation ", et on lit bien "de ma part ", comme si les mots sortaient de la bouche même du personnage.

Acte III. La scène se passe aux thermes de Julien. Le "Romain " ne rêve que du " retour au paganisme " et restera inflexible tout au long de l'acte III, « toujours antique, tout d'une pièce ". C'est ici que Pan se manifeste, avec le cri annonçant sa mort et avec cette " tristesse » dont parlera en 1929 l'auteur du Dernier Retour quand il évoquera le tableau de Signorelli ${ }^{46}$.

Autre " invité ", Henri Heine, avec " les dieux en exil ". Faut-il ici rappeler ce qu'en disait l'auteur des Notes relatives à la religion et aux passions quand il voyait en son Alban " un de ces produits du monde antique adapté à la religion nouvelle à laquelle l'Église les incorpora ": " Je songe à ces divinités champêtres évoquées par Heine " ?

On connaît le thème des Dieux en exil ${ }^{47}$. Le très savant Henri Kitzler a terminé La Magnificence du christianisme, dont il était fort satisfait jusqu'à ce que " quelques écrivains modernes ", parmi lesquels Gibbon, lui révèlent les crimes de ces "chrétiens vainqueurs " qui de persécutés devinrent persécuteurs. Poursuivant son enquête, il découvre les pages où Libanius " conjurait les dévots barbares " d'épargner les temples grecs. Résultat, il prend fait et cause pour le paganisme et jette au feu son manuscrit. Le narrateur intervient alors pour dénoncer la responsabilité des philosophes grecs dans leur lutte contre les Pères de l'Église :

" Il n’importait pas en effet de donner par des subtilités néo-platoniciennes une signification plus profonde à la mythologie, d'infuser aux dieux défunts une nouvelle vie, un nouveau sens symbolique, de se tuer à réfuter la polémique grossière et matérielle de ces premiers pères de l'église, qui attaquaient, par des plaisanteries presque voltairiennes, la moralité des dieux ! - Il importait plutôt de défendre l'essence de l'hellénisme, la manière de penser et de sentir, toute la vie de la société hellénique, et de s'opposer avec force à la

46 Voir plus haut dans le texte. Le tableau, qui se trouvait à Berlin, fut détruit par un incendie en mai 1945.

47 D'abord publié dans la Revue des deux mondes du 15 février 1852, il fut édité chez Lebègue, à Bruxelles, en 1853, puis chez Lévy, à Paris, en 1855, dans le recueil intitulé De l'Allemagne. 
propagation des idées et des sentiments sociaux importés de Judée. La véritable question était de savoir si le monde devait appartenir dorénavant à ce judaïsme spiritualiste que prêchaient ces Nazaréens mélancoliques qui bannirent de la vie toutes les joies humaines pour les reléguer dans les espaces célestes, - ou si le monde devait demeurer sous la joyeuse puissance de l'esprit grec, qui avait érigé le culte du beau et fait épanouir toutes les magnificences de la terre ${ }^{48}$ !"

Dans ce monde christianisé, «Neptune resta le souverain de l'empire des mers, de même que Pluton, malgré sa métamorphose diabolique, conserva le trône du Tartare ». Les habitants de l'Olympe, en revanche, furent moins heureux, et notamment Jupiter, que des marins voyageant dans les mers de glace avaient, parait-il, retrouvé seul et sous les traits d'un vieillard ravagé par les ans dans une île seulement peuplée de lapins où il se lamente désormais sur sa gloire passée.

Que Montherlant ait fait son miel d'un tel récit et qu'il ait songé à s'en inspirer pour son Romain aux thermes de Julien, quoi de plus normal ? Il avait sans doute reconnu dans " la joyeuse puissance de l'esprit grec, qui avait érigé le culte du beau et fait épanouir toutes les magnificences de la terre » ce qu'il avait lui-même écrit en décembre 1912, qu' " au siècle du grand Pan, l'homme sympathisait avec ce qui est sain, ce qui est beau, ce qui est la vie".

Acte IV. Nous voici dans les Vosges (où Julien guerroya en 357 pour le compte de Constance II, où Montherlant a servi de décembre 1917 à juin 1918, à Mirecourt d'abord, comme on l'a vu plus haut, puis à Remiremont, Gérardmer et BandeLaveline), et c'est dans ce contexte qu'il est d'abord question de kyriolés et de pagani.

Le mot pagani, qui l'ignore ? a d'abord désigné les paysans avant de désigner les païens, la campagne étant restée plus longtemps fidèle aux cultes anciens; le mot kyriolés, en revanche, est lorrain et désigne des cantiques populaires comme ceux que chantaient, chaque lundi de Pentecôte, les jeunes filles venues en procession des villages voisins pour honorer l'abbesse et les dames chanoinesses en leur église de... Remiremont. On peut rêver que le païen est ému par ces kyriolés comme le fut en avril 1916, par des "cantiques populaires » lui aussi, l'auteur d'Atlantes ${ }^{49}$, et qu'il découvre, dans un mouvement très " montherlantien ", que " toutes choses sont l'une et l'autre ». Le voilà moins " tout d'une pièce " désormais et animé d'un désir de " conciliation » dans le sens, une fois encore, où l'entendra l'auteur de Syncrétisme et alternance quand il dira "qu'être humain, c'est comprendre tous les mouvements des hommes ", et que " tout le monde a raison, toujours ", et que "l'univers n'ayant aucun sens, il est parfait qu'on lui donne tantôt l'un et tantôt l'autre ${ }^{50}$ ». Dans ce texte cardinal de 1925, Montherlant a repris un mot de Romain Rolland, à qui l'essai était d'abord adressé : "L'humanité est une symphonie de grandes âmes collectives "; ce n'est peut-être pas

48 P. 189 dans l'édition Lévy.

49 L'essai fut intégré dans La Relève du matin (E, p. 111).

50 Voir E, p. 239 et 244, respectivement dans Aux Fontaines du désir. 
un hasard si le mot "symphonie » est aussi celui qui devait terminer l'épisode vosgien : il rappelle les kyriolés, tout en suggérant le syncrétisme.

Acte $V$ et dernier. Comment faut-il entendre le mot " office " ? Notre païen a-t-il assisté à une messe de Pentecôte où l'on chantait de ces kyriolés, à l'image de la messe de Pentecôte qui avait tant ému l'auteur des Enfants du matin ${ }^{51}$ ? A-t-il alors compris, au point d'en tirer une "certitude joyeuse ", que "le catholicisme a tué le christianisme » et qu'il " est en réalité le paganisme continué, tout ce qui nous reste de vivant de la res romana "?

C'est par commodité qu'on a défini les grandes lignes de La Garde autour de Pan comme s'il s'était agi d'un " mystère ", alors que l'épisode qui a pour cadre les thermes de Julien fait davantage penser à un dialogue dans le genre du De Natura deorum auquel l'auteur des Notes relatives à la religion et aux passions renverra bientôt ses lecteurs. Dans ces entretiens philosophiques à l'ancienne, on voit des amis conférer sur les sujets les plus graves dans les lieux les plus aimables qui soient : une palestre, une villa ou le lieu de rencontre par excellence que sont les thermes ${ }^{52}$. Pour La Garde autour de Pan, ceux de Julien s'imposaient, que Montherlant avait découverts, enfant, dans son Malet et qu'il avait sous les yeux en décembre 1922, tandis que les Vosges, et pourquoi pas l'église de Remiremont, auraient servi de cadre à la " révélation ".

Simple hypothèse, bien sûr, que n'infirment ni ne confirment les six feuillets qu'on va lire et dont le contenu même donne à penser que la date figurant sur la page du sommaire est à prendre comme un point de repère à la fois précis et relatif.

FEUILLET 2

1 [coin supérieur gauche au crayon bleu]

espérance : le pain des faibles tout était inutilisé alors qu'aujourd'hui tout est utilisé

Ce qu'il y a eu de beau dans le monde antique, c'est son désintéressement. On vivait, on luttait, on mourait pcq. on avait le talent de vivre et de lutter, de mourir. L'acte était pur, parfait en soi.

Du jour où l'important a été rejeté dans une autre vie, les actes ont perdu leur éminente dignité, sont descendus d'un rang, parce qu'ils n'étaient plus des fins mais des moyens (à cette même époque, les choses inanimées perdirent leur valeur). La vie a perdu sa netteté, paree que rien n'y étaint jamais frnt to talement

51 Cet essai, daté de décembre 1916, fut incorporé, lui aussi, à La Relève du matin (voir E, p. 123).

52 Tous les romans " antiques» de la fin du XIX s. y ont recouru, et Arthur Koestler encore en 1939 pour son Spartacus. Anatole France a choisi le forum pour les personnages de Sur la pierre blanche. 
accompli, puisque cela se continuait dans l'au-delà : excellente justification pour toute médiocrité. À tous les points de vue, le tremblement est entré dans le monde. Il devait y devenir une des nouvelles divinités.

laissent au ciel le soin de punir les coupables. Laissez-vous dépouiller. Ne savez-vous pas que les injustes n'auront pas le royaume de Dieu St Paul, Corinth. I, p. 196 [dans la marge]

Dans le monde ancien, l'homme avait une conscience. C'est pour elle qu'il agissait. Ceci toujours plus ou moins, mais jamais autant que vers ce qu'on a appel(l)é la décadence ro main e. À eettépoque de "déeadenee" Jamais la dignité personnelle n'a été si grande qu'à cette époque de décadence où, la religion étant déconsidérée, Dieu est descendu du ciel pour se mettre dans la conscience de l'homme [dans la marge III, 193]. L'exemplaire de Marc Aurèle marque le plus haut degré de l'accomplissement intérieur. À aucune époque n'a été fait par l'homme un plus violent effort pour se substituer à Dieu. On comprend l'irritation la rage du dieu des Juifs : "Je prendrai les sages dans leurs ruses " - «Le Seigneur connaît les pensées des sages : il sait qu'elles sont vaines » ${ }^{(1)}$

(1) Paul, I Ep. Corinth.

ISRAËL [isolé en bas à droite]

Feuillet 3

21 [coin supérieur gauche au crayon bleu, le 1 surchargeant le 2]

Guign. p. 41 [dans la marge]

lui, c'est une matière religieuse dans cette action $\mathrm{p}$ [arce] qu'il vit moins la coutume des ancêtres, l'hérédité romaine

moi c'est un peuple qui a toujours été digne et à sa hauteur

\section{G. 42 [dans la marge]}

lui un peuple qui a souffert, déporté par le roi de Babylone

exilés, pleins de la croyance à l'obligation de se racheter

une doctrine d'exilés, de patients (Guignebert 46)

cette sorte d'espérance est une chose juive (Guigneb ${ }^{t} 47$ )

le frère du mangeur de sauterelles

p $68 / 74$ sqq. [en dessous et au crayon] 
Feuillet 4

\section{2 [sur le 1] 2 [au crayon bleu sur un bout de papier oblitérant les 1 et 2 précédents]}

Il fallait qu'ils eussent durement souffert pour avoir accepté cette religion qui $1^{\circ}$ renonçait à la vie $2^{\circ}$ était apportée à eux, eitoyens romains, par des circoncis, à eux, hommes libres, par une race infiniment servile ! Certes ils devaient être à leur point de moindre résistance.

Me voici devant lui, semblable à un de ces vieux romains du $1^{\text {er }}$ temps de notre ère, écoutant avec un certain dédain, une certaine répulsion la doctrine qu'apporte Israël. Car lui, se heurtant à l'ordre antique, soudain se trouve allié avec le christianisme : il n’y a plus chrétien d'une part et juif de l'autre ; il est un apôtre chez les Gentils. Il tient pour la religion orientale du Salut ; moi pour la dignité de l'homme pris en soi. Romain et barbare, face à face

Derrière lui il a Isis l'Égyptienne d'Égypte, Cybèle la Phrygienne, Mithra le Perse et le Syrien Adonis

Israël a subi l'influence syro-chaldéenne

Guign 40 et voir tout le haut de la p. 41 [en regard et en dessous de Israël a subi...]

les Nazaréens justification de Pilate p. 54 Guignebert

\section{Feuillet 5}

Onsectemande comment un idéal va pouvoir se substituerà peut être placé moins haut que Il est trop facile de comprendre, par la naturelle faiblesse laisser-aller de l'homme, qu'un autre idéal ait pu se substituer à celui de l'homme qui agit bien parce qu'il est son juge, sans demande, sans espérance et sans recours. Il est plus difficile de comprendre comment il n'y a pas une opinion unanime pour reconnaître loyalement que cet idéal abandonné était eependant plus haut. On voudrait que les chrétiens, qui aiment bien parler de leur faiblesse, reconnussent qu'il y a bien quelque faiblesse dans leur perpétuel besoin de ceci et de cela ; on voudrait que ces tenants du quia absurdum condamnassent la position de l'âme antique autrement morale sans sanction autrement que par un : c'est absurde.

\section{Saugrenu}

pas saugrenu dans l'espèce [dans la marge] conforme à une sa tradition et à son hérédité

un certain nombre de réactions plus extraordinaires à garder que la trace de tel sentiment ou le nez long des difformes

la vie violente étant réapparue ces sentiments peuvent avoir disparu et reviennent [sur un béquet] 
le peuple, toujours en retard, encore païen q[uan]d les cl[asses] cultivées sont chrétien[nes], aujourd'hui croyant q[uan]d les hautes classes sont incrédules, est le grand unificateur, et l'unité etc. (voir Vœu Renaissance) [sur un second béquet]

Feuillet 6

4 [coin supérieur gauche au crayon bleu]

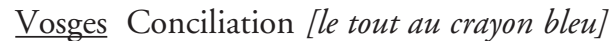

La voix du peuple, surtout des paysans, appelait pour cette conciliation. Toujours en retard (p 14), païen quand ils étaient chrétiens, incroyant quand nous sommes incrédules, la lenteur insensible de sa mutation maintenait une unité et un syncrétisme, mêlait aussi les uns et les autres et appelait pour cette unité de la croyance dont la science a hérité.

Guign $^{\text {bt }} 15$ [dans la marge à la hauteur du texte précédent]

Tayac : entrée de la chapelle - colonnes temple ancien à la rivière

p 17 [référence associée par une flèche à cette unité de la croyance...]

\section{FEUillet 7}

\section{5 [coin supérieur gauche au crayon bleu]}

\section{Office [au crayon bleu]}

Guignebert 236. Revanche du paganisme éternel, re l'Église catholique a rendu supportable le christianisme en le trahissant, en devenant l'Église. Le rôle de l'Église a été de reprendre la tradition romaine et de corriger l'idée évangélique.

Songe

Valery Larbaud

Chacun de ces hommes est un consul etc...

moi, comme les dieux de Heine, un dieu devenu chrétien

Les six pages qu'on vient de lire - autrement dit les feuillets 2 à 7 - développent les points qui figuraient sur la toute première page du manuscrit, à l'exception toutefois du point 1 : "Comment ils deviennent amis dans le Nord », qui n'était sans doute qu'un préambule.

Ce qu'on lit sur la page 1 (feuillet 2) est du pur Montherlant, un premier jet mais de belle venue, et avec quelques corrections qu'on aurait plaisir à relever, tel ce "On 
vivait, on mourait parce qu'on avait le talent de vivre et de mourir » devenu " On vivait, on luttait, on mourait parce qu'on avait le talent de vivre, de lutter, de mourir ».

Pour le fond, on est à mi-chemin des reproches qu'adressait à Jésus le dieu Pan de 1912 : «La vertu n'est vertu que désintéressée. Tout acte de vertu qu'on fera, on le fera par peur de ton enfer, et dans ton ciel immoral, il n'y aura que les égoïstes et les lâches !... ", et des anathèmes qu'on lira en 1929 dans Le dernier Retour comme dans Trois Jours au Montserrat.

"Ce qu'il y a eu de beau dans le monde antique, c'est son désintéressement ", lit-on dans le manuscrit ; et un peu plus loin : "Le tremblement est entré dans le monde. Il devait y devenir une des nouvelles divinités. " L'auteur du Dernier Retour s'en est de toute évidence souvenu, jusqu'à reprendre des formules vieilles de près de sept ans, quand il a décrété qu' " un homme en bonne santé ne s'occupe pas de son âme » :

"Des hommes qui tremblaient de l'âme décidèrent que le tremblement serait le meilleur de l'homme. Dans le Panthéon des grands hommes, ceux qui ont tremblé sont au rayon d'honneur; jamais quelqu'un d'équilibré n'y accédera. À cela désormais rien à faire. La religion du tremblement est une des maladies du monde moderne ; c'est la forme évoluée du convulsionnisme sacré des primitifs ${ }^{53}$."

Et le point de vue est le même dans Trois Jours au Montserrat, où l'auteur, en bon disciple de Lucrèce, décrète que « le Grand Criminel, avec des majuscules, c'est le premier homme qui inventa l'idée de Dieu » et que " c'est bien désespérer de l'humanité, que penser qu'il lui faut une religion pour être haute et pour être honnête ${ }^{54}$ ".

D'où le blâme, si l'on retourne au manuscrit, dirigé contre Paul, pour qui l'homme est jugé après sa mort et toute sagesse vaine aux yeux de Yawhé ${ }^{5}$. De là aussi, a contrario, la réhabilitation de la " décadence ", ou prétendue décadence, qui va de pair avec l'éloge de Marc Aurèle : l'empereur philosophe est devenu pour un païen du IV ${ }^{\mathrm{e}}$ ou $\mathrm{V}^{\mathrm{e}}$ siècle l'image même de la "dignité personnelle ». On s'était demandé, en lisant la toute première page du manuscrit, comment il fallait entendre "leur dignité »; il est clair que pour le païen elle réside dans le "désintéressement ${ }^{56}$ ».

La seconde page 1 (feuillet 3), qui a d'abord porté un numéro $2^{57}$, nous conduit à un ouvrage de Charles Guignebert dont il sera désormais question tout au long des " chapitres » à venir. Le nom de l'ouvrage n'apparaît nulle part dans le manuscrit, mais

53 E, p. 436-437 dans Un Voyageur solitaire.

54 E, p. 400-401 dans Un Voyageur solitaire.

55 C'est bien à l'Épittre I aux Corinthiens, au verset 6, 9, puis au verset 3, 19-20, que renvoie Montherlant, mais les références «p. 196 » et « III, 193 » restent mystérieuses.

56 Inutile de se perdre en conjectures sur le mot Israël en bas de page, aide-mémoire peutêtre pour l'auteur.

57 Il semble en tout cas que c'est bien le 1 qui surcharge le 2, et non l'inverse. 
les références ne laissent aucune place au doute ; il s'agit du Christianisme antique que Guignebert avait fait paraitre chez Flammarion en $1921^{58}$. C'est que Montherlant, qui parle ici pour son héros (" lui-moi»), voulait opposer au païen un Nazaréen ou un converti qui fût conforme à l'histoire. Quand il le définit comme " une matière religieuse ", il cite un mot de Guignebert à la page 41 : «Il y avait là [...] une matière religieuse énorme "; quand il évoque l'exil à Babylone, il est à la page 42 : "Les exilés [...] se persuadèrent que les maux d'Israël venaient de ce qu'il s'était montré infidèle à l'Alliance et qu'il ne lui restait qu'un moyen d'apaiser Dieu, c'était de se soumettre à la plus grande rigueur dans l'observance cultuelle "; quand il affirme que " cette sorte d'espérance est une chose juive ", il se souvient d'avoir lu à la page 47 que «l'espérance messianique dont Israël attendait la réparation éclatante de ses infortunes » allait au contraire "le jeter dans les plus désastreuses aventures ", et s'il écrit de son Nazaréen qu'il est " le frère du mangeur de sauterelles ", c'est pour avoir lu à la page 49 de Guignebert qu' "il se peut que Jésus ait connu Jean le Baptiste ". Quant à dire ce qu'il avait retenu ou se proposait de retenir des pages 68, 74 et suivantes... Peut-être ceci, que les Juifs hellénisés «se pénétraient de plus en plus de l'idée grecque du dualisme de la nature humaine ", et très certainement les pages sur " les combinaisons syncrétistes", comme on va tout de suite le constater en lisant la page 2.

Cette page 2 (feuillet 4), qui fut d'abord numérotée $1^{59}$, est intéressante à plus d'un titre.

Elle est intéressante parce qu'elle donne à lire, comme la première page 1, une forme plus accomplie de l'écriture. Elle est intéressante parce que ses premiers mots : "Il fallait qu'ils eussent durement souffert pour avoir accepté cette religion " préfigurent ceux qu'on lira en 1927 dans La Mort de Peregrinos : "Il fallait être durement excédé pour avoir accepté Jésus-Christ ${ }^{60}$ ", et ceux qu'on lira en 1929 dans Earinus : "Il fallait avoir durement souffert pour accueillir comme un sauveur Jésus-Christ ${ }^{61}$." Elle est intéressante enfin parce qu'on y voit se dessiner la personnalité de "l'autre ».

Cet adversaire pourrait être l'un de ces Romains qui ont accepté une religion par quoi ils " renonçaient à la vie ", se heurtant ainsi à "l'ordre antique " auquel est resté fidèle celui qui parle à la première personne. De cet antagonisme où reparaît la "dignité » dont il fut plus haut question ( II tient pour la religion orientale du Salut ; moi pour la dignité de l'homme pris en soi ") émerge une nouvelle définition de la barbarie : « Romain et barbare, face à face. » Le Barbare, désormais, est celui qui a tout

58 Un ouvrage tout récent par rapport au manuscrit. La BN en a évidemment un exemplaire.

59 Montherlant donne d'abord à cette page un $\mathrm{n}^{\circ} 1$, puis 2 , avant de coller un bout de papier avec un 2 qui confirme son premier remords. On a vu de même sur le feuillet 3 un $n^{\circ} 1$ surchargeant le 2.

60 E, p. 253, dans Aux Fontaines du désir.

61 Dans l'essai Jeux olympiques et Antiquité déjà cité dans la note 8, p. 138. 
absorbé et s'est du même coup renié. À preuve, la suite du texte : "Derrière lui il a Isis d'Égypte, Cybèle la Phrygienne, Mithra le Perse et le Syrien Adonis ", qui vient tout droit de la page $255 \mathrm{du}$ Christianisme antique :

"Le christianisme est une religion orientale par ses origines et par ses caractères fondamentaux; et, s'il était resté ce qu'il fut d'abord, il portait en lui beaucoup moins de chances de conquérir le monde occidental que n'en avait rassemblées la religion d'Isis l'Égyptienne, celle de la Grande Mère Cybèle la Phrygienne, celle du Syrien Adonis ou celle du Perse Mithra. »

Guignebert rappelle en quoi cette religion-là est " plus riche et plus simple que les autres religions du Salut ", et c'est le mot de Montherlant avec sa majuscule. Il dit aussi pourquoi elle pouvait "opposer [...] sa science divine révélée à la vaine sagesse $d u$ monde, qui est folie devant Dieu ", et ce sont les paroles de saint Paul qu'on a lues un peu plus haut. Il explique enfin comment " dès le II ${ }^{\mathrm{e}}$ siècle elle s'ouvrit aux désabusés de la philosophie profane ${ }^{62}$ ", autrement dit : "Il fallait qu'ils eussent durement souffert pour avoir accepté cette religion. "

Restent les notes que Montherlant a griffonnées, en deux temps, au bas de cette page 2, et qui n'ont pas toutes le même intérêt. Dans la mesure où on vient d'en lire l'essentiel sous une forme achevée qui dérive de la page 255 du Christianisme antique, on peut tenir les renvois aux pages 40 et 41, ainsi que les mots «Israël a subi l'influence syro-chaldéenne ", pour les aléas d'un brouillon. Mais ce qu'il faut considérer de près, c'est la toute dernière ligne : "Les Nazaréens justification de Pilate p. 54 Guignebert. "

Pilate était une belle matière pour les écrivains. Qui ne se rappelle Le Procurateur de Judée d'Anatole France ou le Ponce Pilate de Roger Caillois ${ }^{63}$ ? On connaît moins la " nouvelle " intitulée La Mort de Pilate que Montherlant composa en 1908, à treize ans, mais dont il fut assez content pour en confier l'édition près de trente ans plus tard à son ami Ventura García Calderón : obsédé par la vision du "Nazaréen en croix » et persuadé que seule la mort lui apportera la " guérison ", l'homme va se noyer dans une rivière proche de Jérusalem ${ }^{64}$. Celui qui avait écrit, adolescent, cette Mort de Pilate ne pouvait que retenir, adulte, la page où Guignebert s'étonne que d'aucuns veuillent " prouver que, si Jésus ne s'est pas lui-même avoué ouvertement Messie, il a cru qu’il l'était, il l'a laissé croire à ses disciples, il a péri pour l'avoir laissé croire à Pilate ; et que,

62 Le Christianisme antique, p. 257.

63 Les récits de France (1891) et de Caillois (1961), pour passionnants qu'ils soient, relèvent surtout de la légende de Pilate. Le Pilate de l'Histoire, c'est celui de Jean-Pierre Lémonon dans le Ponce Pilate qu'il a publié en 2007 aux Éditions de l'Atelier.

64 La nouvelle occupe les pages 90 à 97 d'Explication de Montherlant, Bruxelles, Les Cahiers du Journal des Poètes, Série Essais, $n^{\circ} 41$ de septembre 1937. M. Barat m’a communiqué le texte original, que Montherlant avait intégré dans le carnet Érold et Sylvaine; il n'y a que fort peu de différences entre les deux versions. 
s'il en avait été autrement, jamais les Apôtres n'auraient pu penser que le Crucifié était ressuscité des morts».

Le chapitre 3 de La Garde autour de Pan était censé se passer aux thermes de Julien, mais si le manuscrit compte bien une page 4 intitulée «Vosges Conciliation » qui correspond au chapitre 4 et une page 5 intitulée "Office " qui correspond au chapitre 5 , on n'y voit aucune page 3 qui développe le chapitre 3 «Aux thermes de Julien ». On $\mathrm{y}$ trouve seulement une page sans numéro (le feuillet 5) où furent collés deux béquets. C'est même la note figurant sur le second béquet, encore que l'argument ne soit pas très solide $^{65}$, qui nous fera lire cette page avant la page "Vosges Conciliation ». Cela étant, le texte lui-même réserve quelques surprises. Sinon le texte continu, où Montherlant revient sur l'idéal désintéressé du monde antique tout en opposant aux chrétiens leurs inconséquences et leur intransigeance, en tout cas celui des deux béquets.

Le "saugrenu " du premier béquet ${ }^{66}$, c'est l'épithète que " la critique catholique " avait décernée à l'Alban du Songe et que Montherlant réfutera dans ses Notes relatives à la religion et aux passions : celui qui passe pour saugrenu ne l'est que pour la société de son temps ; replacé « dans son espèce », le voilà " conforme à sa tradition et à son hérédité ». Quant au second béquet, s'il retient l'attention, c'est moins pour le texte, qu'on retrouvera page 4, que pour l'allusion, dans la parenthèse " (Voir Vœu Renaissance) ", à l'ouvrage de Joséphin Péladan publié en 1905 chez Sansot.

Jean-François Domenget a bien défini l'intérêt de Montherlant pour cet auteur fin-de-siècle que fut le Sâr Péladan ${ }^{67}$. Il a ainsi relevé, dans les Malatestiana des années cinquante, une note où l'écrivain se retranche derrière Le Vou de la Renaissance pour justifier une réplique de son Porcellio, l'assassin de Malatesta ${ }^{68}$, et dans des carnets de la même période, une note où, présentant son œuvre comme une « œuvre de réconci-

65 On pourrait s'épuiser en conjectures, se fonder par exemple sur les différences d'écriture (car Montherlant n'a pas utilisé le même stylo tout au long des dix pages), ou sur les différences de support (un des "versos " témoigne d'un échange, daté des 16 et 21 mars 1922, entre l'écrivain et la revue France-Amérique).

66 Ce béquet est découpé dans la lettre circulaire décrite dans la note 2.

67 Il faut ici lire les pages 29, 38, 40 et 173 de son Montherlant critique qui parut à Genève, chez Droz, en 2003.

68 Voici le texte des Malatestiana: "La réplique de Porcellio : "En tant qu'homme raisonnable, je ne crois pas en Dieu. Mais en tant que chrétien baptisé, je suis bien obligé d'y croire", est authentique, mais dans la bouche d'un autre humaniste, cité par Péladan (Le Vou de la Renaissance)" (T, p. 427), et voici le texte de la p. 47 du Vou de la Renaissance, d'où il ressort que Montherlant a davantage exploité le commentaire de Péladan que le mot de Pomponace cité par lui : " "L'immortalité de l'âme ne souffre de ma part aucun doute, puisque les Écritures canoniques qui doivent être préférées à toute raison et à toute expérience, confirment cette thèse. Mais l'objet de mon doute, c'est de savoir si cette thèse n'excède pas les limites de la raison." Voilà du comique philosophique et de l'excellent comique. Comme chrétien Pomponace croit ; comme philosophe, il ne croit pas. » 
liation " (c'est quasiment le chapitre 4 de La Garde autour de Pan), il renvoie le lecteur " à ce livre de Péladan, Le Voeu de l'unité [sic], où Péladan disait que ce vœu fut celui des hommes de la Renaissance ${ }^{69}$ ".

D'irréfutables témoignages que renforcent ceux qu'on grappillera dans les parages immédiats du manuscrit, à commencer par l'article que Montherlant avait publié dans Les Écrits nouveaux de janvier 1921 sous le titre Pour l'anniversaire de Paul $A d a m^{70}$. Jeune écrivain, il se rallie à la majorité pour saluer en lui « un homme de la Renaissance ", mais " en partie " seulement, et quand il range parmi ses vertus " le pli de juxtaposer sans exclure ", il se permet une restriction : "Encore que les Renaissants aient cherché une conciliation que lui ne cherchait pas ", où l'on reconnaît l'empreinte de Péladan autant que le leitmotiv de notre manuscrit ${ }^{71}$.

Mais enfin, la marque la plus évidente du Voeu de la Renaissance est en aval du manuscrit, dans le final des Notes relatives à la religion et aux passions où se dessine l'image de l'homme qui " réalise tout l'humain » et à qui revient le droit de chanter l'hymne à la gloire du Père que Péladan produisait comme une preuve de la hauteur d'âme de Laurent le Magnifique :

Grand Dieu! toi dont la loi régit cet univers

et entre l'âme dans ce corps

[...]

de toi, premier auteur, tout prend sa vie ${ }^{72}$.

Faut-il encore, après cela, tenir pour un hasard que l'ami Faure-Biguet, dans l'opuscule qu'il publia en 1925 sous le titre Montherlant homme de la Renaissance,

69 Garder tout en composant tout, Paris, Gallimard, 2001, p. 214, dans une note du 27 janvier 1954 intitulée "Garder tout en composant tout ». Un peu plus loin dans cette même note, l'écrivain, parlant du catholicisme comme de quelque chose qui «n'est pas cru, mais accueilli ", ajoute qu'il est "accueilli à une place secondaire, comme Jésus qui a sa place dans le panthéon d'Alexandre Sévère ". Il corrigeait ainsi l'erreur qu'il avait commise en 1940 dans Paysage des Olympiques (et qu'il reproduira en 1972 dans Mais aimons-nous ceux que nous aimons ?) lorsqu'il imputait à Septime Sévère, empereur de 193 à 211, un éclectisme qui fut en réalité celui d'Alexandre Sévère, empereur de 222 à 235, ou du moins l'éclectisme que lui attribue l' Histoire Auguste quand elle rapporte qu'il avait un laraire où l'image du Christ voisinait avec d'autres (H. A., Alex. Sev., XXIX, 2).

70 Voir la note 14 pour les références.

71 Sans oublier, peu après, l'éloge appuyé de « ces régions où nulle chose ne rompt de façon formelle avec une autre, où le paganisme épuré d'un Platon ne contredit en rien d'important le christianisme et d'où l'on voit se lever au lointain le vieux rêve d'une pensée libre et d'une vie libre dans le sein de la communauté catholique " (Les Écrits nouveaux, p. 5 et 10 ; Au Petit Mutilé, p. 55 et 70). Pour tout ce qui concerne Montherlant et Adam, voir, ici encore, J.-Fr. DOMEnGeT, Montherlant critique, p. 33-41, passim.

72 P. 70 du Voeu de la Renaissance et, dans une version légèrement revue, p. 13 et 14 du placard (769 de la $N r f)$. 
ait rapproché telle ou telle page de la Première Olympique des écrits d'un Pic de la Mirandole ou d'un Marcile Ficin tant célébrés par Péladan ? Faut-il s'étonner qu'il ait enfin évoqué Le Vou de la Renaissance en précisant que " ce vœu, c'était l'unité 73 "?

On a suggéré que le chapitre "Dans les Vosges » du sommaire avait pour cadre un lieu de prières dans un milieu rustique et que le païen, le "saugrenu ", avait alors pris conscience de l'indifférence de toutes choses, l'indifférence selon Montherlant, c'est-à-dire celles de Pyrrhon ("À toute raison s'oppose une égale raison ") et de Montaigne ("Il n'y a raison qui n'en aye une contraire ») ${ }^{74}$. Il n'est rien dans la page "Vosges Conciliation » qui n'aille dans le même sens. Quand on lit que « la voix du peuple [...] appelait pour cette conciliation ", on se rappelle ce qu'écrivait en décembre 1916 l'auteur des Enfants du matin, qu'avec le plain-chant "nous recréons quelque chose de l'âme antique ${ }^{75}$ ". Il parlait alors d'un "ethos» de la musique, l'ethos dans La Garde autour de Pan jaillit de l'appel «pour cette unité de la croyance dont la science a hérité ».

Que viennent faire ici, cependant, les pages 14 et 15 du Christianisme antique?

Guignebert, après avoir rappelé que " chaque société se façonne la religion qui lui convient ", mais aussi que " dans une même société, chaque milieu social [...] se crée de cette religion une variété qui réponde à ses besoins particuliers ", commence par donner un exemple qui ne pouvait échapper à l'attention de Montherlant : "Aux derniers temps de la République romaine la religion des esclaves retardait de deux ou trois siècles sur celle de leurs maîtres. " Après quoi il explique que le peuple « d'instinct $[\ldots]$ s'attache toujours [...] à une conception et à une pratique religieuses qui ne correspondent exactement ni à l'enseignement de la religion officielle, ni à la mentalité de ses ministres instruits, ni à la représentation de ses dogmes et de ses préceptes qui prévaut parmi les fidèles éclairés »; il dit encore que " cette religion populaire se révèle à l'analyse comme un syncrétisme, un mélange de croyances et d'usages, divers par l'origine, l'âge et le sens, et qui ne subsistent côte à côte que parce que ceux qui les acceptent ne les comparent jamais "; il termine en disant que "le peuple, et particulièrement celui des campagnes, ne fait jamais tout à fait table rase de ses croyances et de ses rites ", mais qu' "il les adapte spontanément à la religion nouvelle qui s'impose à lui, ou bien, si elle s'y refuse, les refoule au tréfonds de sa conscience et dans le secret de sa vie, où ils durent à l'état d'actives superstitions ». Condensé par Montherlant, cela donnait sur le béquet de la page précédente "Le peuple, toujours en retard etc. ", avant d'aboutir à la version de "Vosges Conciliation " :

73 Montherlant, homme de la Renaissance, p. 43 et 63-64 respectivement, Plon-Nourrit et $\mathrm{C}^{\text {ie, }}$, 1925.

74 «L'univers n'ayant aucun sens, il est parfait qu'on lui donne tantôt l'un et tantôt l'autre ", dira l'auteur de Syncrétisme et alternance (E, p. 244).

75 E, p. 121 dans La Relève du matin. 
« La voix du peuple, surtout des paysans, appelait pour cette conciliation. Toujours en retard, païen quand ils étaient chrétiens, croyant quand nous sommes incrédules, la lenteur insensible de sa mutation maintenait une unité et un syncrétisme, mêlait aussi les uns et les autres et appelait pour cette unité de la croyance dont la science a hérité. »

La difficulté sera de démêler dans cette version revue ce que Guignebert appelait le milieu social. C'est bien le païen, l'incrédule d'aujourd'hui, qui parle du peuple, dont il se démarque parce qu'il fait lui-même partie des "classes cultivées ", mais pourquoi " quand ils étaient chrétiens ", plutôt que " quand nous étions chrétiens " ? Un lapsus de Montherlant, qui tout juste après corrigera "incroyant " en " croyant " ? Ce n'est peut-être qu'une question de perspective : " nous » valant pour "nous aujourd'hui », " ils", pour " nous hier".

On hésitera moins sur la clausule " cette unité de la croyance dont la science a hérité ", associée par Montherlant à une page 17 qu'il faut chercher non pas chez Guignebert mais dans Le Vou de la Renaissance, quand Péladan proclame que " le vœu admirable des humanités fut sans cesse de travailler à la paix spirituelle, c'est-à-dire de concilier les doctrines, d'établir leurs concordances, pour préparer cette unité idéale de la croyance dont la science a hérité ${ }^{76}$ ". De quoi éclairer a posteriori les mots " et l'unité etc. " qu'on a lus sur le second béquet du précédent feuillet, tout en conférant à cette page "Vosges Conciliation » un statut proprement littéraire : ce ne sont pas de banales notes de lecture, c'est un texte élaboré, avec un de ces « arrangements » qu'affectionnait Montherlant.

Reste la note sur Tayac, l'entrée de la chapelle et les colonnes du temple ancien à la rivière. Une note qui pour le fond annonce la mosquée de Tolède convertie en église ou la "colonne engagée " de la façade de Sainte-Marie in Cosmedin que Mathilde Pomès signale à Montherlant quand elle le guide dans Rome en octobre 1947 : "Il tire son calepin, prend une note ; cette colonne reparaîtra. Ce sera la colonne de la collaboration (le paganisme forcé de servir le christianisme) ${ }^{77}$. " Mais enfin 1922 n'est pas 1947, ni 1925. "Tayac » est le souvenir du stage bucolique en Dordogne auquel fut astreint, en août 1917, le soldat Montherlant. Envoyé aux Eyzies après une semaine à l'École militaire, le nouvel engagé gagne Périgueux, qui le déçoit, puis les Eyzies-deTayac, qui le ravit. Il fait même, à cette occasion, de longues promenades le long de la Vézère, allant à pied jusqu'à Saint-Léon, où il visite " une église bâtie sur un ancien temple romain, car il aime par dessus tout, comme il l'écrit alors à sa grand-mère,

76 Un texte qu'on trouve à vrai dire aux pages 19 et 20 du Vou de la Renaissance, mais on aura la faiblesse de croire que c'est par inadvertance que Montherlant a écrit 17 plutôt que 19. Cette référence à la p. 17 fut du reste notée, comme il ressort très clairement du manuscrit, après la note sur Tayac.

77 À Rome avec Montherlant, p. 14, André Bonne, 1951. 
ces “combinaisons pagano-chrétiennes ${ }^{78 " ~ » . ~ L a ~ n o t e ~ d e ~} 1922$ sur Tayac ${ }^{79}$, c'est quelque chose de similaire à ce " kyriolés " du premier feuillet qui nous avait ramenés au Remiremont de 1918 dans les Vosges.

Les premières lignes de la page intitulée Office (feuillet 7) s'accordent si étroitement avec le point 5 du plan initial : "Se rend compte que le catholicisme a tué le christianisme et est en réalité le paganisme continué, tout ce qui nous reste de vivant de la res romana. Certitude joyeuse ${ }^{80}$ ", qu'on pourrait se passer de les commenter, ou se contenter de lire, avec Montherlant, les pages 236 et suivantes du Christianisme antique, où Guignebert oppose à la " religion du prophète galiléen, humble et doux » le christianisme " universaliste et guerrier » du Moyen Âge qu'il voit comme un retour du paganisme :

"Il semble que, sous le nom du Christ, ce soit la vie philosophique et religieuse du paganisme, avec tous ses contrastes et toutes ses incohérences, qui ait repris vigueur et triomphé de la religion en esprit et en vérité que le Maître juif avait vécue. »

La conclusion de Guignebert est sans équivoque :

"C’est la vie gréco-romaine tout entière qui revêt une apparence chrétienne et elle se juxtapose à cet idéal qui la désavoue sans la gêner. Le grand résultat visible, au seuil du $V^{\mathrm{e}}$ siècle, c'est [...] que le triomphe du christianisme n'a été, à tous points de vue, qu'une apparence et que, loin d'avoir transformé le monde gréco-romain, il a été réellement absorbé par lui [...]. Et parce que c'est l'Église, en tant qu'elle est devenue une puissance de gouvernement et, comme telle, qu'elle a incliné aux compromis et aux concessions,

78 Pour tout cet épisode, voir P. SipRIOT, Montherlant sans masque, p. 84-87. Lorsque Montherlant parle de l'église Saint-Léon comme d'une église « bâtie sur un ancien temple romain ", il reprend une théorie qui était admise en 1917. On est aujourd'hui plus nuancé. Max Sarradet, par exemple, dit qu' « il semble qu'elle fasse suite à un lieu de culte remontant à la fin de la période gallo-romaine " "Fouilles archéologiques dans l'église de Saint-Léon-sur-Vézère (1961-1962) ", p. 73-100 dans Documents d'Archéologie et d'Histoire Périgourdines, t. 8, 1993, article qui me fut généreusement fourni par la Mairie de Saint-Léon-sur-Vézère).

79 Montherlant parle d'une chapelle, alors que Saint-Martin de Tayac est une église-forteresse, mais qui sans doute n'avait pas en 1917 l'allure qu'elle a maintenant retrouvée. Pour ce qui est des colonnes provenant d'un temple ancien, rien de plus vrai : l'une des archivoltes du portail repose sur deux colonnes antiques de marbre vert qui pourraient provenir de l'antique Vesunna (et je remercie au passage l'Office de Tourisme Terre de Cro-Magnon et M. Bernard Coste de la Bibliothèque municipale de Périgueux, qui m’ont aidé dans toutes ces recherches). Pourquoi Montherlant a-t-il ajouté « à la rivière » ? Parce qu'il était admis en 1917 que ces colonnes avaient été repêchées dans la Vézère, ou qu'elles avaient été transportées par bateau de Vesunna à Tayac ? À moins qu'il n'ait voulu écrire "face à la rivière ", l'entrée de l'église Saint-Martin se trouvant face à la Vézère.

80 Voir le feuillet 1. 
parce que c'est l'Église qui a triomphé dans de pareilles conditions, après s'être identifiée au christianisme, c'est elle qui est responsable de l'inévitable résultat ${ }^{81}$. "

On est à plein dans La Garde autour de Pan, qu'il s'agisse du point 5 du plan initial, la joie de celui à qui on ne sait quel office a révélé la connivence de l'Église et du paganisme, ou des premières lignes de la page 5 : «Revanche du paganisme éternel, l'Église catholique a rendu supportable le christianisme."

Reste à faire un sort aux quelques annotations qui terminent cette page 5 :

"Songe / Valery Larbaud / Chacun de ces hommes est un consul etc. / moi, comme les dieux de Heine, un dieu devenu chrétien. »

Les allusions au Songe et aux dieux de Heine sont limpides pour qui se souvient de l'image que donnera de Bricoule l'auteur des Notes relatives à la religion et aux passions: " Je songe à ces divinités champêtres évoquées par Heine..." .

"Chacun de ces hommes est un consul etc. » semble amorcer une citation (de la même façon qu'au feuillet 5 « et l'unité etc. " annonçait la formule de Péladan qui fut incorporée au texte de "Vosges Conciliation»), et s'il en est ainsi, le mot serait lié à la "donation " qu'aurait faite Constantin au pape Sylvestre pour le remercier de l'avoir guéri de la lèpre. L'humaniste Lorenzo Valla, explique Péladan, avait été le premier à dénoncer le caractère apocryphe de ce document qui fondait " la dignité impériale " de Sylvestre et de ses successeurs, et il avait pointé les assimilations qui le rendaient d'emblée suspect : "Les révérendissimes clercs sont assimilés à des sénateurs ; on les crée tous patrices et consuls. Ils auront des chevaux caparaçonnés de blanc ${ }^{82} \ldots$ " Simple hypothèse, faut-il le dire.

On hésitera beaucoup moins pour Valery Larbaud, que Montherlant tenait alors pour " un très grand écrivain ${ }^{83}$ " et qu'il faut ici voir comme le père spirituel du Joanny Léniot de Fermina Márquez.

Ce Léniot a de l'Église une vision proche de celle de Bricoule. Il est " partisan d'un retour à l'hégémonie impériale romaine, telle que cette hégémonie existait sous Constantin et sous Théodose ", et s'il déplore que Clovis, sous sa " pourpre consulaire ", n'en fut " pas moins roi des Francs ", il s'en console en reconnaissant dans l'Église « ce qui reste de l'Empire ":

"Je ne suis pas français. Mon catéchisme me dit que je suis catholique romain, et moi je traduis cela ainsi : Romain et maître du monde ! Mon souverain, mon unique maître, c'est [...] le divin-auguste Léon, empereur d'Occident ! [...] Lorsque je regarde l'autel, ce ne sont pas des cierges allumés, des draps et des fleurs d'or, c'est la majesté romaine que je vois. Le prêtre, les fidèles, tous sont assemblés là en qualité de catholiques romains ;

81 Le Christianisme antique, p. 236 à 239, passim.

82 Le Vou de la Renaissance, p. 56.

83 Voir ici encore Domenget, Montherlant critique, p. 137, texte et note 14. 
autant dire, de Romains, n'est-ce pas ? La Ville est aux mains des infidèles ; les divinités de l'Empire sont tous les jours insultées ; et cependant, ceux qui sont dans cette maison se glorifient d'être appelés Romains. Ô mânes de Caton, voici les derniers citoyens !... Là, dans cette maison du Seigneur, j'entends parler encore la langue de ma vraie patrie : le latin ${ }^{84}$."

Cet acte de foi sui generis a dû plaire à Montherlant, lequel méditait sans doute, fin 1922, l'essai Tibre et Oronte qu'il mettra bientôt en tête de sa Première Olympique en le datant du 15 août 1923. On connaît les "principes » de cette dissertation :

"Deux philosophies se disputent le monde, où elles ont tour à tour installé leur empire. L'une, féminine dans son génie, est fondée sur l'invérifiable [...]. Née en Orient [...], elle a enfanté l'utopie, qui a enfanté le désordre. Alexandrinisme, messianisme, christianisme, byzantinisme, Réforme, concepts de liberté et de progrès, Révolution française, romantisme, humanitarisme (libéralisme, cosmopolitisme, pacifisme), bolchevisme enfin, voilà de ses génitures. Sur son sceau est gravé un cœur. L'autre, virile, est fondée sur la nature et la raison : esprit et corps. Elle tient pour le fini et elle tente d'y réaliser l'ordre, c'est-à-dire une valeur de qualité. Elle a atteint son expression la plus complète dans la Rome antique, après la conquête de la Grèce. Elle a inspiré le catholicisme romain, la Renaissance, les concepts de tradition et d'autorité, le classicisme, les nationalismes, les protectionnismes matériels et moraux ${ }^{85}$."

Une idéologie de cette sorte, où le christianisme et le catholicisme romain sont tenus pour des valeurs "répugnantes ", se situe, comme on voit, dans le droit fil de $L a$ Garde autour de Pan aussi bien que du Christianisme antique de Guignebert. Et la suite est de la même farine : l'essayiste exalte les vertus "doriennes ", en clair le sport, qu'il pratiquait en ces temps-là avec assiduité ${ }^{86}$, déplore que l'heureuse combinaison du spirituel et du temporel, " retrouvée à la Renaissance, confortée par les papes, vivifiée en quelques créatures ", ait été ruinée par Luther, et cite, dans un mouvement comparable à celui qu'on a vu dans les Notes de mai 1923, l'exemple de ses aïeux (le trisaïeul guillo-

84 Fermina Márquez, p. 353-355, passim dans le vol. Euvres de la Bibl. de la Pléiade, Paris, Gallimard, 1984. Ce sera l'occasion de signaler que Léniot est, comme son créateur, un lecteur assidu de l'Histoire des Romains de Victor Duruy et qu'il fait l'éloge de La Cité antique de Fustel de Coulanges et du Cicéron et ses amis de Gaston Boissier, autant d'ouvrages qui ont beaucoup compté pour Montherlant.

85 Première Olympique Le Paradis à l'ombre des épées, p. 7-8, Grasset, "Les Cahiers verts", $\mathrm{n}^{\circ} 31,1924$. Le titre de l'essai inaugural s'inspire d'un vers de Juvénal : «Il y a beau temps que l'Oronte syrien s'est déversé dans le Tibre. " (Iam pridem Syrus in Tiberim defluxit Orontes - III, 62.)

86 Montherlant, sur ce point, se démarque du personnage de Larbaud. Alors que Théodose symbolise pour Léniot "l'hégémonie impériale romaine », pour l'auteur de Tibre et Oronte il est le chrétien qui ruina la gymnastique en supprimant les Jeux Olympiques (Le Paradis à l'ombre des épées, p. 9). 
tiné par une Révolution " dirigée contre la survivance spirituelle de Rome », le bisaïeul légitimiste et ultramontain, le grand-père zouave pontifical défendant par les armes "l'héritage des Césars »), qu'il ne voit pas comme des " tenants du catholicisme », mais bien comme les "tenants d'un ordre du Tibre dont le catholicisme fait partie ".

Cela posé, Montherlant s'est assez vite distancié de ces " généralisations " qu’il qualifiait, dès 1926 , de "bulles de savon intellectuelles ${ }^{87}$ ", et s'il conserva dans toutes les éditions des Olympiques la conclusion de Tibre et Oronte, en bref « La grande affaire n'est pas de renoncer. La grande affaire est de garder tout en composant tout ${ }^{88}$ ", il y pratiqua aussi quelques élagages lourds de sens : éliminée la symbolique du Tibre et de l'Oronte ; disparue l'exaltation de «la minute complète » où la Trinité " Force, beauté, mystique " se traduisait "Rome, Athènes, Bethléem "; gommée l'idée d'un catholicisme perçu comme "un gage donné au pacte social ${ }^{89}$ ".

Ces considérations, en fait, s'accordaient mal avec l'homme qui, le 15 janvier 1925, quitte la France " avec deux valises " pour devenir le "voyageur traqué " qui se découvrira dans Aux Fontaines du désir, La petite Infante de Castille, Un voyageur solitaire est un diable. Et le temps n'est pas si éloigné où on le verra prendre ses distances avec l'idéal prôné dans les Notes relatives à la religion et aux passions. À preuve, ce qu'on lira au tout début de 1929 dans Earinus :

"Essayer, comme je l'ai fait durant toute mon adolescence, et jusqu'à ces dernières années, de concilier une foi catholique sincère avec l'amour des corps, pour leur beauté et pour leurs réalisations, cela peut être un idéal respectable et touchant, - ce fut celui de la Renaissance. Ce ne peut être jamais, je le crois aujourd'hui, qu'une position fausse de l'esprit ${ }^{90}$."

À preuve aussi, les pages de Trois Jours au Montserrat où se renforcera l'idée, le Port-Royal de Sainte-Beuve ayant semé sa graine, qu'on ne peut " prendre le christianisme au sérieux " qu’à la condition de choisir " la voie qui toujours se rétrécit ". On l'a vu plus haut, Montherlant reconnaitra volontiers - alors - que " chercher à concilier Pan et Jésus-Christ " est un " exercice " réservé à ceux qui, comme lui, sont "à l'extérieur du catholicisme ${ }^{91}$ ", et encore l'exercice est-il franchement aléatoire :

87 À l'occasion d'un article qu'il consacre à Louis Hémon dans Les Nouvelles littéraires du 6 février (voir Domenget, Montherlant critique, p. 92).

88 P. 16 à 24 dans l'édition originale, sous le titre "L'Angelus sur le Stade ", et p. 157-163, comme Note, dans l'édition de 1938 regroupant les deux Olympiques (R1, p. 307-309).

89 P. 20 et 21 de l'édition originale.

90 Earinus, p. 132 touchant un essai publié en 1924 sous le titre Sport et catholicisme. À rapprocher de ce qu'on a lu dans Mais aimons-nous ceux que nous aimons ?: "Dans ces années-là, 1920 et 1921 , les prêtres..."

91 E, p. 398-399. Il est remarquable que ces considérations aient longtemps figuré en marge de Service inutile. On les trouve encore en 1943 dans l'édition bruxelloise de la Toison 
" J'incline volontiers à respecter Jésus-Christ, sans croire en lui, mais que le soleil se lève, que retentisse une musique entraînante, me voici païen, qui me reprends au monde. Et inversement, quand j'en serai à la satiété. Les autres font de même : tel croit parce qu'il a pleuré, ou parce qu'il a eu une déception sentimentale, ou parce qu'il vieillit. Tel autre ne croit plus parce qu'il a vu un mauvais prêtre. [...] Voilà le sérieux de nos opinions $^{92}$."

Une note manuscrite en marge de Pour une Vierge noire (de Trois Jours au Montserrat, si l'on préfere ${ }^{93}$ ) permettra de faire le point :

« Il y a unité dans mon œuvre de 1920 à 1925, et unité nouvelle de 1925 à 1930 [...]. Dans Les Bestiaires qui sont de 1926, je me plaisais à mêler encore, comme dans Le Songe, catholicisme et paganisme. Aujourd'hui, dans La Vierge noire, je reconnais qu'il n'y a là qu'un jeu de l'imagination et de la poésie. Le christianisme est autre chose [...], l'idée que je me fais de lui me permet de le respecter beaucoup plus que quand je le mêlais aux mythes païens des premiers siècles. "

Le " tour de valse avec le sacré " de mai 1923 a fini par prendre les allures d'une valse-hésitation. Ce que confirme à sa manière le dossier "Sur la Religion » qu'on lira dans le prochain numéro d'Anabases avant d'en revenir - pour son volet « Julien » - au manuscrit de 1922 .

Pierre DuroIsIN

480/8, chaussée de Wavre

B-1040 Bruxelles

duroisin.lenglez@scarlet.be

d'or (p. 24, note 1) et en 1947 dans l'édition Laffont (p. 23-24, note 2) ; elles ne figurent plus dans l'édition de la Pléiade.

92 E, p. 986 dans des carnets de 30-31. On a noté l'allusion au mot de Chateaubriand : "J'ai pleuré et j'ai cru."

93 L'équation est un peu abusive, mais on renvoie ici le lecteur à la note 15. Quant au texte qu'on va lire, on le trouve sur la Toile dans le lot $n^{\circ} 167$ du catalogue de vente de Piasa du jeudi 11 avril 2002. 


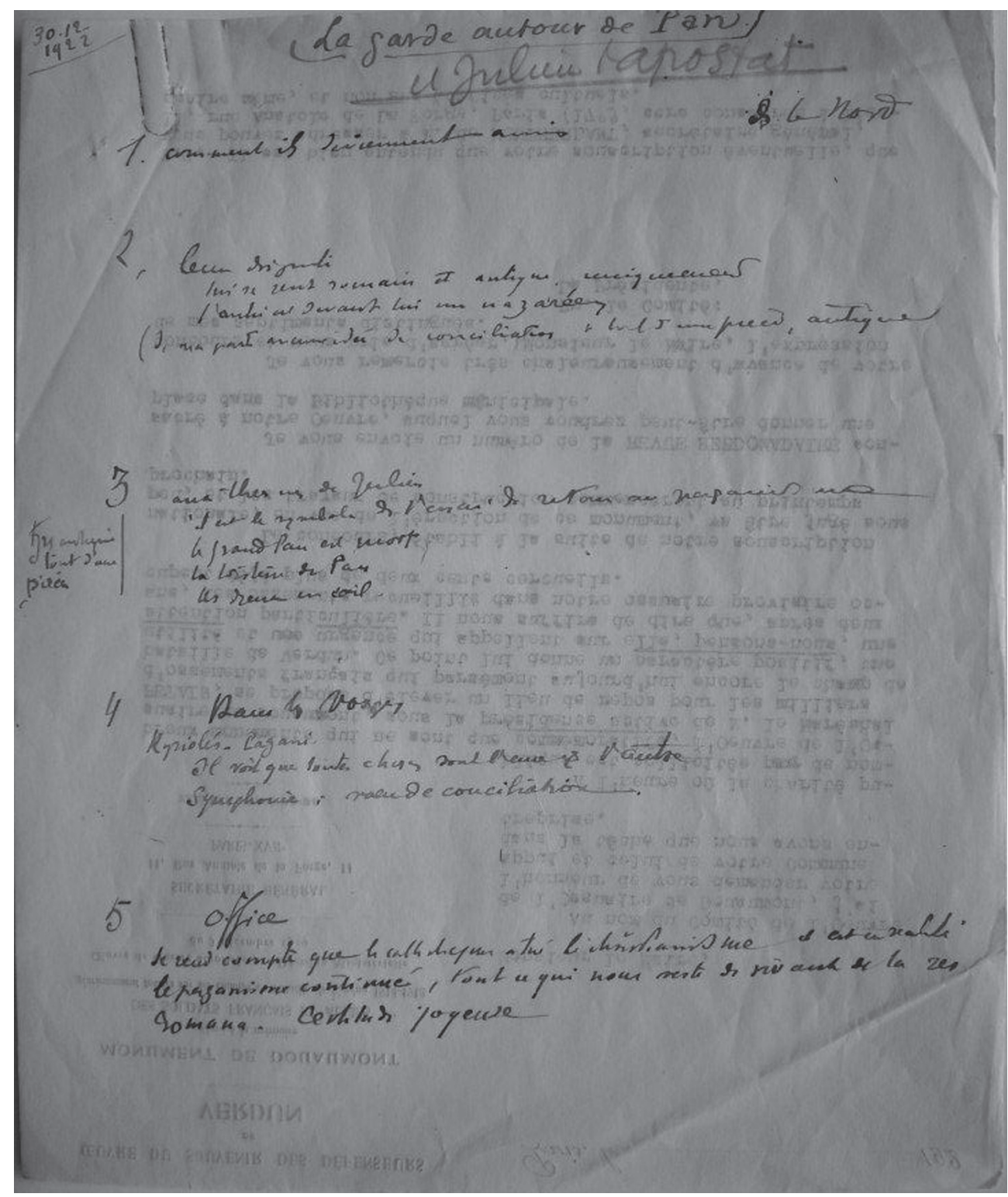

Feuillet 1 
HENRY DE MONTHERLANT « ENTRE LES DEUX MONDES »

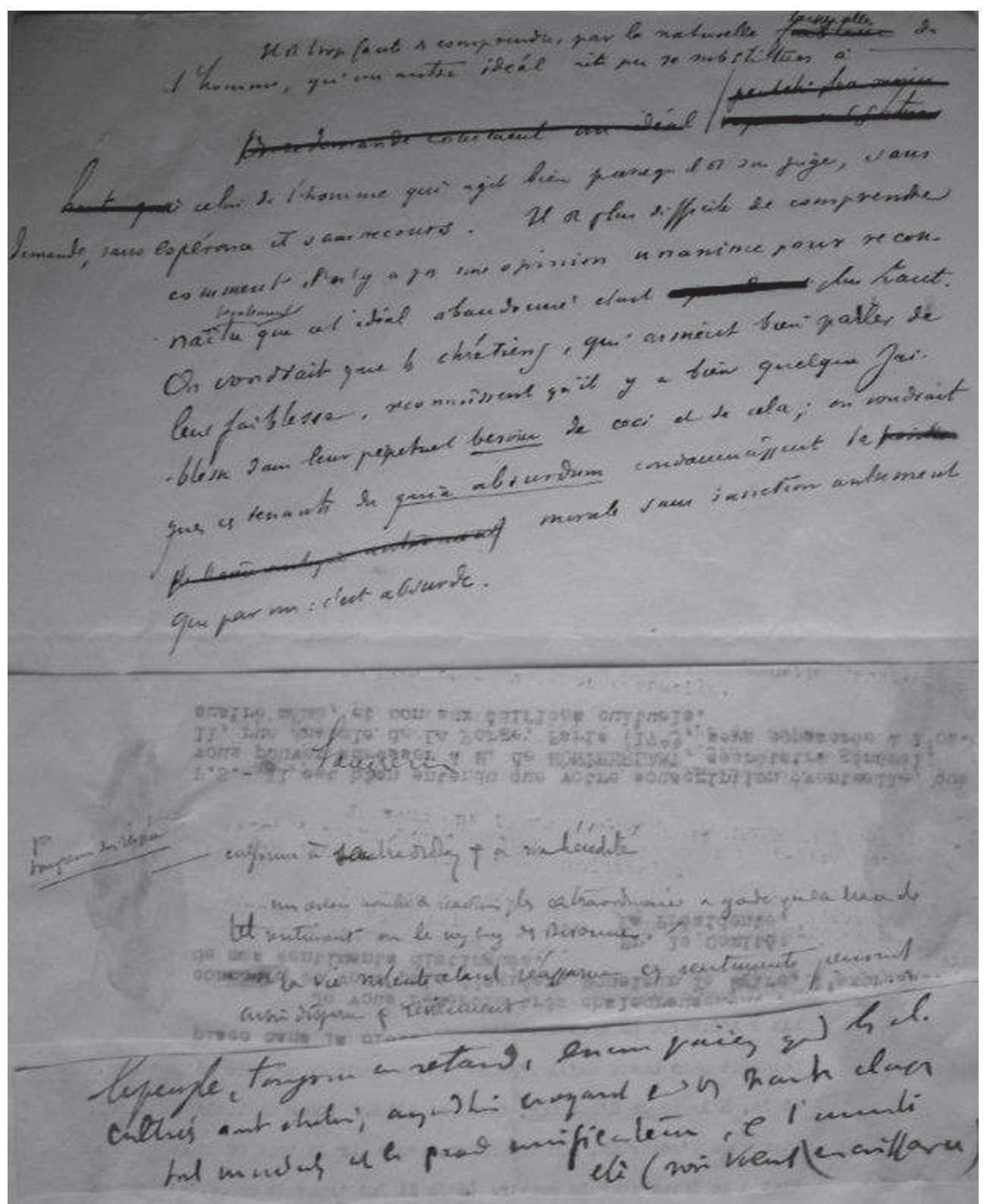

Feuillet 5

83 